\title{
Amyloid Oligomer Neurotoxicity, Calcium Dysregulation, and Lipid Rafts
}

\author{
Fiorella Malchiodi-Albedi, ${ }^{1}$ Silvia Paradisi, ${ }^{1}$ Andrea Matteucci, ${ }^{1}$ \\ Claudio Frank, ${ }^{2}$ and Marco Diociaiuti ${ }^{3}$ \\ ${ }^{1}$ Dipartimento di Biologia Cellulare e Neuroscienze, Istituto Superiore di Sanità, Viale Regina Elena 299, 00161 Rome, Italy \\ ${ }^{2}$ Centro Nazionale Malattie Rare, Istituto Superiore di Sanità, Viale Regina Elena 299, 00161 Rome, Italy \\ ${ }^{3}$ Dipartimento di Tecnologie e Salute, Istituto Superiore di Sanità, Viale Regina Elena 299, 00161 Rome, Italy
}

Correspondence should be addressed to Fiorella Malchiodi-Albedi, fiorella.malchiodi@iss.it

Received 2 November 2010; Revised 7 December 2010; Accepted 8 December 2010

Academic Editor: Katsuhiko Yanagisawa

Copyright ( 92011 Fiorella Malchiodi-Albedi et al. This is an open access article distributed under the Creative Commons Attribution License, which permits unrestricted use, distribution, and reproduction in any medium, provided the original work is properly cited.

\begin{abstract}
Amyloid proteins constitute a chemically heterogeneous group of proteins, which share some biophysical and biological characteristics, the principal of which are the high propensity to acquire an incorrect folding and the tendency to aggregate. A number of diseases are associated with misfolding and aggregation of proteins, although only in some of them-most notably Alzheimer's disease (AD) and transmissible spongiform encephalopathies (TSEs) — a pathogenetic link with misfolded proteins is now widely recognized. Lipid rafts (LRs) have been involved in the pathophysiology of diseases associated with protein misfolding at several levels, including aggregation of misfolded proteins, amyloidogenic processing, and neurotoxicity. Among the pathogenic misfolded proteins, the $\mathrm{AD}$-related protein amyloid $\beta(\mathrm{A} \beta)$ is by far the most studied protein, and a large body of evidence has been gathered on the role played by LRs in $\mathrm{A} \beta$ pathogenicity. However, significant amount of data has also been collected for several other amyloid proteins, so that their ability to interact with LRs can be considered an additional, shared feature characterizing the amyloid protein family. In this paper, we will review the evidence on the role of LRs in the neurotoxicity of huntingtin, $\alpha$-synuclein, prion protein, and calcitonin.
\end{abstract}

\section{Introduction}

Lipid Rafts (LRs) are highly dynamic, nanoscale domains of the plasma membrane, enriched in cholesterol and sphingolipids (Figure 1). They were originally defined on the basis of their resistance to solubilization in nonionic detergents, which allows their separation and isolation from the rest of the plasma membrane, using sucrose-density gradients [1]. Although their existence has initially been questioned [2, 3], it is now generally agreed that LRs are special membrane domains that act as platforms for the organization and interaction of proteins [4]. They are involved in several cell functions and play crucial roles in signal transduction, phagocytosis, protein sorting, and cell polarity. Besides the role in cell physiology, they are also involved in cell pathology. For example, certain pathogens, such as viruses and bacteria, as well as their toxins, interact with the host cells through LRs $[5,6]$. In the pathogenicity of amyloid proteins, LRs have been implicated in amyloidogenesis, in the process of protein aggregation, in the mechanisms of interaction between the cell membrane and amyloid proteins, and in their neurotoxic effect. This paper will first provide an overview on the principal milestones in the history of amyloid proteins. After considering the mechanisms of neurotoxicity of misfolded proteins, it will then focus on the role played by LRs in the interaction between neuronal cells and four amyloid proteins: huntingtin (htt), $\alpha$-synuclein $(\alpha$ syn), prion protein (PrP), and calcitonin (CT).

\section{The Amyloid Protein History: Breakthrough Discoveries}

The history of amyloid proteins has been for a long time, with a few, though remarkable, exceptions, the history of $\mathrm{A} \beta$. $\mathrm{A} \beta$ was first isolated in 1984 from brain blood vessels of $\mathrm{AD}$ patients and individuals with Down's syndrome 


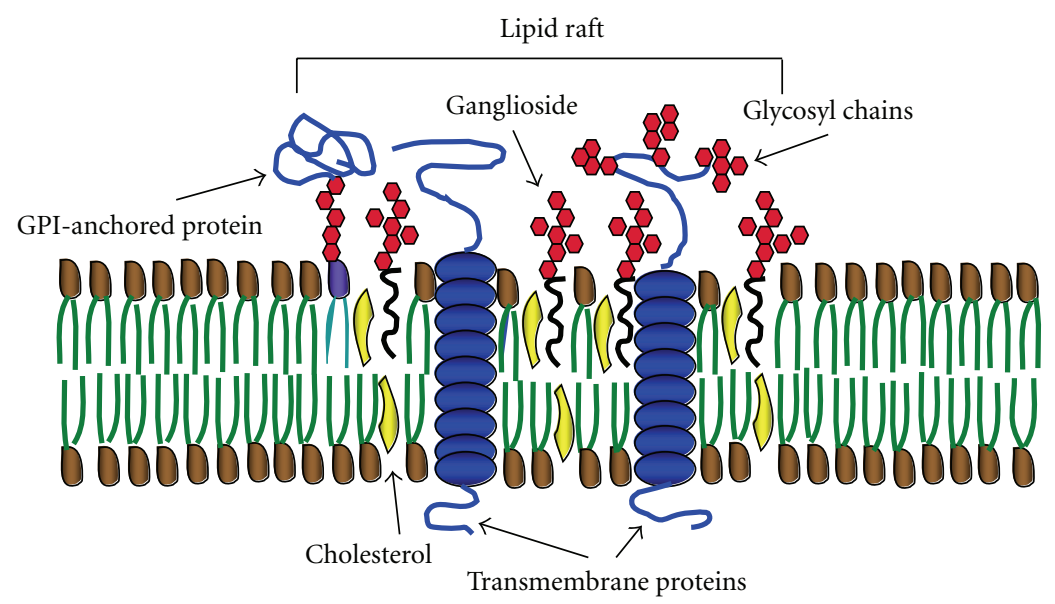

FIGURE 1: Schematic representation of an LR in the cell membrane, enriched in gangliosides and cholesterol. Glycosylated and nonglycosylated transmembrane proteins and GPI-anchored proteins are also sketched.

[7, 8]. In 1985, Colin Masters identified $\mathrm{A} \beta$ as the principal component of amyloid plaques, the hallmark of $\mathrm{AD}$, and in collaboration with Konrad Beyreuther identified the amino acid composition, the molecular mass, and the $\mathrm{NH} 2$ terminal sequence of the peptide [9]. In addition, they recognized that the protein was identical to that described for the amyloid deposited in the congophilic angiopathy of $\mathrm{AD}$ and Down's syndrome [9]. In the same year, the first evidence was provided that prion proteins ( $\mathrm{PrP}$ ) assemble into filaments within the brain to form amyloid plaques into scrapie-infected hamsters [10]. The discovery of prions dated back to 1982, when the Nobel Prize winner Stanley B. Prusiner described them as novel proteinaceous infectious agents causing scrapie [11]. At the beginning of the 1990s, experiments on primary neuronal cultures showed that aggregated $\mathrm{A} \beta$ peptides were neurotoxic in vitro, suggesting a link between amyloid formation and neurodegeneration [12]. Since then, primary hippocampal cell cultures have been considered as an ideal cell culture model to study neurotoxic properties of amyloid proteins. In the same years, breakthrough discoveries on the genetics of $\mathrm{AD}$ (for a review, see [13]) led to formulate "the $\mathrm{A} \beta$ cascade hypothesis." According to this theory, the $1-42$ and $1-40 \mathrm{~A} \beta$ peptides, deriving from the proteolytic cleavage of the amyloid $\beta$ precursor protein, operated by the $\beta$ and $\gamma$ secretases, are the principal culprits in the development of $\mathrm{AD}[14,15]$. In the 1990s, the understanding of pathogenic mechanisms of AD dramatically advanced due to the introduction of transgenic animal models, which have provided invaluable insights into several aspects of $\mathrm{AD}$ pathophysiology (for a review, see [16]), although mice that precisely model all aspects of $\mathrm{AD}$ are not yet available [17]. In the same years, studies on other misfolded proteins started to accumulate. In 1993, the HTT gene, associated with Huntington's disease (HD), was identified [18]. It was shown that, in the mutated htt protein, a polyglutamine tract was abnormally expanded, leading to high aggregation propensity. In 1997, Spillantini et al. identified $\alpha$-syn as the fibrillary component of Lewy bodies (LBs) in Parkinson's disease (PD) and dementia with LBs
[19]. In the same years, the first data suggesting a common neurotoxic mechanism of all amyloid proteins were provided [20]. Although aggregation was considered a critical process in the pathogenicity of $\mathrm{A} \beta$ from the beginning, it was not until the end of the 1990s that attention focused on the role of amyloid oligomers more than amyloid fibrils [21]. These studies also identified in the synapse a special target of soluble oligomer toxicity [22], providing a biological explanation to the well-known clinical-pathological observation that dementia in $\mathrm{AD}$ has a good correlation with the synapse loss, while the amyloid burden is a poor predictor of cognitive decline [23, 24]. Furthermore, they demonstrated that $\mathrm{A} \beta$ oligomers can impair long-term potentiation (LTP), an experimental form of synaptic plasticity resulting in longlasting increase in the strength of synaptic transmission, which is the electrophysiological counterpart of learning and memory [25].

In the same period, attention shifted from the insoluble amyloid fibrils to the soluble oligomeric aggregates also for other amyloid proteins, which were found to be neurotoxic. They included both disease-associated proteins, such as islet amyloid polypeptide (IAPP), $\alpha$-syn, PrP, and polyglutamine [26], and non-disease-associated proteins, such as HypF-N, a protein that is not associated with any amyloid disease but displays an aggregation-prone behavior [27]. These amyloid oligomers were found to form pores on model membranes with ion channel properties [28], a mechanism originally proposed for $A \beta[29]$, and the induced $\mathrm{Ca}^{2+}$ dysregulation was proposed as a common pathogenetic mechanism through which all amyloid proteins lead to neurotoxicity [30].

One of the latest "coups de theatre" in the amyloid history is the observation that PrPC is a high-affinity cell-surface receptor for soluble $\mathrm{A} \beta$ oligomers on neurons and is a mediator of $\mathrm{A} \beta$ oligomers-induced synaptic dysfunction [31]. This hypothesis, however, has been challenged by several authors [32-34] and has become a highly controversial issue, still far from being settled [35]. 


\section{Amyloid Proteins: A Large Family of Unrelated Proteins with Some Shared Features}

Though differing in the amino acid sequences, amyloid proteins share the tendency to adopt an incorrect conformation (protein misfolding) and the propensity to aggregate. Until recently, there was a general agreement on the idea that only a limited number of proteins can undergo aggregation. However, it has been recently shown that the characteristics that enable a protein to become amyloid are present in almost all complex proteins and that the number of amyloid proteins is limited because the region promoting aggregation is generally hidden [36].

The process of aggregation is complex, depending on characteristics intrinsic to the protein and to environmental conditions and proceeds through several organization states, including dimers, trimers, tetramers, low molecular weight prefibrillar oligomers, and linear or annular protofibrils, to reach the final insoluble fibrillar structure, rich in $\beta$ sheets. The term "amyloid" should more correctly refer to the mature fibrils, which deposit in tissues and are characterized by Congo red and Thioflavin T positivity. In some diseases, such as systemic amyloidosis, these deposits have a pathogenetic role, and the disease is caused by the deposition of mature fibrils. In neurodegenerative conditions associated with protein misfolding, however, it is now generally agreed that the pathogenic forms are not the mature fibrils but the intermediate, soluble oligomeric aggregates $[21,25,37]$. Oligomers of different amyloid proteins have a remarkable structural similarity, evident at Transmission Electron Microscopy (TEM) and Atomic Force Microscopy (AFM), showing an annular morphology with sizes ranging from 8 to $12 \mathrm{~nm}$, a morphology sustaining the amyloid pore hypothesis (see below). In addition, conformation-specific antibodies have been raised, which cross-react with a number of chemically unrelated misfolded proteins, recognizing generic epitopes exposed in similar folding states of the different proteins [38].

Among the shared features, we believe that three characteristics deserve special attention: oligomeric aggregate pathogenicity, synaptotoxicity, and propagation of protein misfolding.

3.1. Pathogenicity of Oligomeric Aggregates. Besides AD, a role for pathogenic oligomeric amyloid species has been suggested for other protein misfolding diseases, most notably for $\mathrm{PD}, \mathrm{HD}$, and PrP diseases.

$\mathrm{PD}$ is the second most common neurodegenerative disease affecting aging populations, after $\mathrm{AD}$. The characteristic symptoms of PD include rigidity, resting tremor, postural instability, and bradykinesia. The disease characteristically affects the substantia nigra, where dopaminergic neurons accumulate proteinaceous aggregates, referred to as LBs and degenerate. The majority of patients suffering from PD have a sporadic form of the disease, apparently with no genetic cause, while $5-10 \%$ of patients have mutations in a series of genes referred to as the PARK genes [39]. Among the proteins encoded by these genes, $\alpha$-syn has been the object of consid- erable interest, since it constitutes the principal component of LBs [19]. Intracellular, $\alpha$-syn-positive inclusions are also present in dementia with LBs and multiple system atrophy, which, together with PD, are collectively referred to as synucleinopathies [19]. $\alpha$-syn shows a distinctive propensity to aggregate, a phenomenon associated with a conformational change from random coiled to predominantly $\beta$-pleated sheet [40,41]. This characteristic is enhanced when $\alpha$-syn is mutated or overexpressed, as in some familiar forms of PD and has been correlated to the pathogenesis of the disease $[41,42]$. It is assumed that the aggregation process proceeds through progressive stages, from monomers, through partially folded intermediates, up to mature fibrils. As for $A \beta$, increasing evidence suggests that prefibrillar oligomers and protofibrils, rather than mature fibrils, are the pathogenic species in PD $[41,43]$. Two mutations in the $\alpha$-syn gene, linked to autosomal dominant early-onset PD, have been described to promote the formation of transient protofibrils at a higher rate than wild-type $\alpha$-syn [42], although both wild-type and mutant $\alpha$-syn have been shown to form porelike structures in synthetic vesicles and model membranes $[28,44,45]$. The pore formation, inducing disruption of cellular ion homeostasis, may be responsible for the neurotoxic effect [44]. Although the question is still open [46], data obtained in three established model systems for PD, such as mammalian neurons, the nematode Caenorhabditis elegans, and Drosophila melanogaster, show a strong correlation between $\alpha$-syn aggregates with impaired $\beta$-structure, neuronal toxicity, and behavioral defects [47], further sustaining a pathogenic role for $\alpha$-syn oligomers in PD. Evidence on a role of phosphorylation in the oligomerization and neurotoxicity of $\alpha$-syn has also been provided [48].

HD is a late-onset, autosomal dominant disorder clinically characterized by chorea, cognitive impairment, and psychiatric disorders. The mutation responsible for $\mathrm{HD}$, an expanded CAG repeat sequence in the HD gene, leads to a polyglutamine expansion in the amino-terminal portion of the htt protein. Although the physiopathology of the disease has not been fully clarified, a role for protein misfolding is suggested by the observation that HD occurs when htt expands beyond around 35 glutamine residues, a modification that facilitates protein aggregation and the acquisition of $\beta$ sheet structure [49]. In lymphoblasts from HD patients and medium spiny striatal neurons of the YAC72 HD mouse model, polyglutamine expansion in htt was accompanied by cytosolic and mitochondrial $\mathrm{Ca}^{2+}$ overload, triggering an apoptotic pathway [50,51]. As for many other misfolded proteins, htt aggregation is a complex process advancing through a variety of different assemblies, eventually leading to the formation of insoluble inclusion bodies. The different aggregative intermediates have probably different biological activities. As described for $\mathrm{A} \beta$ and other misfolded proteins, the soluble aggregates, more than the insoluble inclusion bodies, are probably the neurotoxic species [26].

Prion diseases, also known as TSE, are progressive, mostly fatal neurodegenerative diseases. They include Creutzfeldt-Jakob disease, Gerstmann-Sträussler-Scheinker disease, kuru and fatal familial insomnia in humans, bovine spongiform encephalopathy in cattle, scrapie in sheep, 
and chronic wasting disease in deer and elk. The central pathogenic event in these diseases is the conversion of the PrPC, a normal cellular isoform, into the abnormal PrPSc (where Sc stands for "scrapie"). The conversion determines an increase in the $\beta$-sheet content of the protein and is accompanied by changes in biological and biochemical properties of PrPSc, such as increased resistance to proteases and propensity to form amyloid fibrils. The interaction between PrPC and pathogenic PrPSc is supposed to determine a template-induced, progressive deposition of new PrPSc, which accumulates in brain tissue as dense plaquelike amyloid deposits, perivascular deposits, or diffuse, nonfibrillary deposits, reminiscent of synaptotoxic oligomeric $\beta$ amyloid aggregates. Although the deposition of amyloid plaques is a hallmark of prion diseases, recent studies suggest that, in analogy to $\mathrm{A} \beta$ and other amyloid proteins, the soluble oligomeric aggregates of PrPSc are the actual neurotoxic species. For example, prefibrillar oligomers are neurotoxic in vitro and in vivo [52], and soluble oligomeric species are most efficient in transmitting TSE [53]. It has also been proposed that the fibrillar form of PrP, which is typically observed at autopsy, may actually be neuroprotective [54].

3.2. Synaptotoxicity. Amyloid proteins are, by definition, neurotoxic. Neuronal cell damage induced by various amyloid proteins has remarkable analogies, especially considering one highly specific effect: synaptic dysfunction. Compromised synaptic function is a key event in the pathogenesis of AD. Quantitative evaluation of temporal and frontal cortical biopsies revealed a significant decrease in the density of synapses [55]. At autopsy, synapse loss, as demonstrated by decrease in synaptophysin immunolabeling, showed a clear-cut correlation with the severity of dementia [56]. Later on, it has been shown that synapse loss is an early event in the pathophysiology of the disease [56]. More subtle derangements of synaptic activity, induced by $A \beta$ oligomers, precede synapse loss. The studies by Selkoe and collaborators have shown that natural $\mathrm{A} \beta$ oligomers, secreted from cultured cells, when injected in rat brain, potently inhibit LTP, enhance long-term depression (LTD), and impair the memory of learned behaviors in rats $[25,57$, 58]. Similar results were obtained from $A \beta$ dimers isolated from the brain of $\mathrm{AD}$ patients [59]. Evidence for a role of synaptic dysfunction in PD, HD, and PrP diseases has also been collected, showing modified synaptic activity as a consequence of the interaction with misfolded proteins. Synaptic dysfunction is an early symptom in $\alpha$-syn-induced pathology $[60,61] . \alpha$-syn is localized at synapses, where it is involved in the modulation of synaptic transmission and neuronal plasticity [62], in the regulation of the size of different pools of synaptic vesicles [63], and in the SNARE complex assembly [64]. Recently, it has been demonstrated that $\alpha$-syn directly regulates the dynamics of actin microfilaments, whose integrity is fundamental in synaptic vesicle mobilization, recycling, and exocytosis. This regulatory activity was profoundly altered in the A30P mutation, associated with familial PD [65]. Using paraffinembedded tissue blot and protein aggregate filtration assays, it has been shown that the majority of $\alpha$-syn oligomeric aggregates are located at presynaptic terminals, suggesting an impact on synaptic function $[66,67]$. This is also sustained by the observation that, in cultured neurons from brains of transgenic mice overexpressing human $\alpha$-syn, excessive $\alpha$-syn induced a decrease in other presynaptic proteins, leading to morphologic and functional changes of synapses [68].

Studies in animal models of HD have clearly shown that synaptic dysfunction precede neuronal loss [69-71]. Decreased pre- and postsynaptic markers and altered glutamate release were found at the corticostriatal synapse before the onset of motor symptoms [72]. Altered LTP and LTD were early electrophysiological signs of aberrant synaptic plasticity $[73,74]$. In a Drosophila HD model, expanded fulllength htt was observed to increase neurotransmitter release efficiency, leading to impairment of synaptic transmission and altered $\mathrm{Ca}^{2+}$ homeostasis [75].

In prion diseases, synaptic alterations are among the pathognomonic pathologic features, together with neuronal loss, spongiform change, astrocytosis, and deposition of amyloid aggregates. Immunocytochemical localization of PrPSc has a dot-like appearance around neuronal cell bodies and, along dendrites, reminiscent of synaptic protein localization in synapses [76, 77]. There is evidence that synaptic changes precede neuronal death [78-81], possibly sustained by mitochondrial dysfunction [82]. Mice with prion diseases can be cured at the stage of early synaptic dysfunction and impairments at neurophysiological, behavioural, and morphological levels are reversible [83]. Interestingly, the fact that reversible changes precede extensive accumulation of PrPSc deposits suggest that they may be caused by a transient neurotoxic species [84], in analogy with the effects of soluble oligomeric $\mathrm{A} \beta$ in $\mathrm{AD}$.

3.3. Propagation of Protein Misfolding. In $\operatorname{PrP}$ diseases, the key molecular event is the conversion of the PrPC into the infectious PrPSc, which serves as template to produce further, aggregation-prone PrPSc. Emerging evidence seems to converge towards the theory that the ability to form autoperpetuating amyloid aggregation is not exclusive to PrPSc. These findings suggest that several proteins, belonging to the amyloid family, accumulate and propagate through a nucleation-dependent aggregation, starting from what has been defined as an "amyloid seed," whose presence facilitates further oligomerization of the proteins [85].

One of these proteins is $A \beta$. Injection of brain extracts from human $\mathrm{AD}$ brains, but not from control age-matched patients, in transgenic mice overexpressing the $\mathrm{A} \beta \mathrm{PP}$, induced extensive $\mathrm{A} \beta$ deposition $[86,87]$. The increased $\mathrm{A} \beta$ production did not occur when $\mathrm{AD}$ brain extracts were depleted of $A \beta$ [87], suggesting that infused $A \beta$ can act as an amyloid seed. The process has also been characterized in vitro, showing that homogenates from SHSY5Y cells, which had uptaken $\mathrm{A} \beta$, were capable of seeding amyloid fibril growth [88]. Aggregation of $\alpha$-syn is also a nucleationdependent process. In vitro biophysical studies have shown that the process is accelerated by the presence of preaggregated protein [89]. This mechanism has also been demonstrated in cells, where $\alpha$-syn aggregates, but not 
monomers, can induce the formation of LB-like aggregates [90]. In addition, injection of preformed oligomeric aggregates in cells overexpressing $\alpha$-syn determines the formation of highly filamentous intracellular, $\alpha$-syn-positive inclusions [91]. Cross-seeding between different amyloid proteins has also been described. For example, pure $\alpha$-syn and tau facilitate each other aggregation [92]. Amyloid fibril formation of $\alpha$-syn is accelerated by preformed amyloid seeds of other amyloid proteins, such as Escherichia coli chaperonin GroES, hen lysozyme, and bovine insulin [93]. Susceptibility of different peptides toward cross-seeding is related to the intrinsic aggregation propensity of the peptides [94].

Cell-to-cell propagation of protein misfolding, characteristic of prion diseases, has been described for $\alpha$-syn in cell cultures and animal models of PD [95]. Furthermore, it has been observed that transplanted neurons in $\mathrm{PD}$ patients develop in time LB and PD pathology, suggesting the propagation of $\alpha$-syn aggregation from host cells to graft cells $[96,97]$. This phenomenon may have important clinical implications. For example, efficacy of stem cell therapies in these diseases may be hampered by the risk of propagation of protein misfolding from the host cells to transplanted stem cells $[98,99]$.

\section{Mechanisms of Amyloid Neurotoxicity: The Role of $\mathrm{Ca}^{2+}$ Dysregulation}

Although there is now wide agreement on the role played by amyloid oligomers in neurotoxicity, the mechanisms through which they induce neuronal cell dysfunction and, eventually, cell death are not fully understood. A number of different possibilities have been explored, including mitochondrial dysfunction, lysosomal failure, and abnormal activation of signalling pathways. These mechanisms may or may not accompany a more general neuronal cell derangement, which is a common effect of the interaction of amyloid proteins with neuronal cells, $\mathrm{Ca}^{2+}$ homeostasis dysregulation.

In resting neurons, cytosolic $\mathrm{Ca}^{2+}$ concentration is maintained around 100 nanomolar, while the extracellular concentration is about $1 \mathrm{mM}$ and that of intracellular $\mathrm{Ca}^{2+}$ stores, the endoplasmic reticulum (ER) and mitochondria, is between 100 and $500 \mu \mathrm{M}$. $\mathrm{Ca}^{2+}$ entry from the extracellular space occurs through ligand-gated, voltage-gated, and storeoperated $\mathrm{Ca}^{2+}$ channels, while $\mathrm{Ca}^{2+}$ release from intracellular stores, mainly represented by the ER, are regulated by inositol trisphosphate receptors and ryanodine (RyR) receptors. Recently, it has been reported that presenilin I, an integral membrane protein whose mutations cause early-onset inherited $\mathrm{AD}$, also functions as $\mathrm{ER} \mathrm{Ca}^{2+}$ leak channel [100, 101]. The tight regulation of $\mathrm{Ca}^{2+}$ concentration gradient depends on the crucial roles played by $\mathrm{Ca}^{2+}$ ions in neuronal cell processes, including neurotransmitter release, generation of action potential, gene expression, synaptic plasticity, and neurite growth. In addition, excessive intracellular $\mathrm{Ca}^{2+}$ concentrations may activate a number of pathogenic responses, whose overall effects are modulation of membrane excitability and enzyme/kinase activity, induction of gene expression, formation of reactive oxygen/nitrogen species, mitochondrial dysfunction, and apoptosis/necrosis.
To explain the genesis of $\mathrm{Ca}^{2+}$ dysregulation in diseases associated to misfolding and aggregation of amyloid proteins, two main mechanisms have been postulated: the activation of preexisting ion channels and the formation of calcium-permeable amyloid pores.

4.1. Activation of Preexisting Ion Channels. Interaction with several $\mathrm{Ca}^{2+}$-permeable channels has been described for amyloid proteins, potentially leading to an intracellular $\mathrm{Ca}^{2+}$ rise. As usual, most evidence derives from experiments on $\mathrm{A} \beta$. The glutamatergic system has been thoroughly studied, on the basis of the role played by glutamate receptors in the excitotoxic neuronal cell damage, whose overstimulation leads to excessive intracellular $\mathrm{Ca}^{2+}$ rise [102]. Several in vitro studies showed that incubation of neuronal cultures with $\mathrm{A} \beta$ oligomers increased $\mathrm{Ca}^{2+}$ influx through N-methyl-Daspartate (NMDA) receptors. The moderate-affinity, uncompetitive NMDA receptor antagonist memantine protects against $\mathrm{A} \beta$ oligomer toxicity by attenuating intracellular $\mathrm{Ca}^{2+}$ increase [103]. Currently, memantine is the only approved treatment for $\mathrm{AD}$, besides acetylcholinesterase inhibitors, although the therapeutic efficacy is limited [104]. $\mathrm{A} \beta$ oligomers induce dynamin 1 degradation, which may endanger synaptic integrity. This effect is mediated by NMDA receptor activation [105]. Interactions of $A \beta$ with other $\mathrm{Ca}^{2+}$ permeable channels have been documented, such as voltage-gated $\mathrm{Ca}^{2+}$ channels $[106,107]$. An involvement of nicotinic acetylcholine [108-110], catecholamine [111], and serotonin receptors [112] has also been postulated in $\mathrm{Ca}^{2+}$ dysregulation following $\mathrm{A} \beta$ treatment.

Intracellular $\mathrm{Ca}^{2+}$ stores have also been implicated in $\mathrm{Ca}^{2+}$ dysregulation. When presenilin is mutated, its function as ER $\mathrm{Ca}^{2+}$ leak is disrupted, contributing to $\mathrm{Ca}^{2+}$ dysregulation $[100,101]$. Exaggerated intracellular $\mathrm{Ca}^{2+}$ levels have also been put in relation to modulation of $\mathrm{Ry} R$ receptors [113].

A role for calcium-permeable channel has been described for other amyloid proteins. $\mathrm{Ca}^{2+}$ influx via $\mathrm{N}$-type voltagedependent $\mathrm{Ca}^{2+}$ channels has been described following $\alpha$ syn treatment in rat synaptosomes [114]. Overactivation of NMDA receptors, followed by an abnormal neuronal $\mathrm{Ca}^{2+}$ signaling, is believed to play a role in $\mathrm{HD}$ pathogenesis $[50,115,116]$. Activation of glutamate receptors has been described to be induced by HypF-N [117].

4.2. The Calcium-Permeable Pore Hypothesis. To explain $\mathrm{Ca}^{2+}$ dysregulation, a different mechanism has been hypothesized: amyloid oligomers may form nonselective calciumpermeable pores. This ability, originally described for $\mathrm{A} \beta$ [29], has also been described for other misfolded proteins and has been proposed as a common property of the amyloid protein family $[28,30]$. Several pieces of evidence sustain this hypothesis. Cribbs et al. [118] showed that both D- and L-stereoisomers of truncated form of $\mathrm{A} \beta$ were neurotoxic in vitro. This observation argues against a role for specific ligand-receptor interaction in the mechanism of toxicity. Morphological studies at TEM and AFM levels have shown that oligomers of many amyloid proteins, such as $\mathrm{A} \beta$ and $\alpha$ syn [44], serum amyloid A, amylin [28], and CT [119], have 
a characteristic annular morphology, reminiscent of cationpermeable membrane pores [120]. Furthermore, TEM analysis has also revealed the presence of $A \beta$ pore-like structures in the cell membrane of brains from $\mathrm{AD}$ patients but not from age-matched healthy patients [121]. Treatment of SHSY5Y cells with a wide range of oligomeric, but not fibrillary, amyloid proteins, including $\mathrm{A} \beta$, PrP, IAPP, polyglutamine, and lysozyme, induced increase in intracellular calcium. The increase could not be attributed to activation of endogenous $\mathrm{Ca}^{2+}$ channels, because the responses were unaffected by the potent endogenous $\mathrm{Ca}^{2+}$ channel blocker cobalt [30]. Electrophysiological recordings using model membranes showed heterogeneous single-channel conductances for several amyloid proteins [28]. Finally, it has been proposed that protein aggregates may mimic bacterial pore-forming toxin, which permeabilize membranes forming oligomeric pores characterized by $\beta$-sheet structure [122].

The different hypotheses are not mutually exclusive and can cooperate towards $\mathrm{Ca}^{2+}$ dysregulation. Recently, it has been proposed that amyloid oligomers may act at two steps, separated in time, a first, very rapid step, where $\mathrm{Ca}^{2+}$ increases due to glutamate receptor stimulation by the oligomers, followed by a second, delayed step, where oligomers permeabilize nonspecifically the cell membrane, possibly via the formation of amyloid pores [117].

\section{Lipid Rafts and Amyloid Neurotoxicity}

From the original description [123], the concept of LR has remarkably evolved. The introduction of high-resolution imaging techniques (for a review, see [124]) and the progress in lipidomics and proteomics methodologies have revealed that LRs have a highly heterogeneous composition and are characterized by an extremely dynamic structure. LRs can now be defined as nanoscale assemblies of sphingolipid, cholesterol, and proteins, fluctuating in a more fluid phospholipid matrix. By finely tuning lipid-lipid, proteinlipid, and protein-protein interactions, they can coalesce, forming more stable structures and providing functional platforms for crucial membrane activities, such as signaling and trafficking [124].

Considerable amount of data suggest the involvement of LRs in the interactions between amyloid proteins and cell membranes. Some crucial information has been obtained through the use of biophysical techniques on model membranes (for a review, see [125]), which will be briefly illustrated. Most of the work focused on the interactions between LRs and A $\beta$. However, compelling evidence has also been obtained for htt, $\alpha$-syn, PrP, and CT, which will be reviewed here.

\section{Using Model Membranes to Study Amyloid Proteins}

6.1. Model Membranes. The use of model membrane systems has remarkably improved our knowledge on the biochemistry of amyloid proteins, providing information about the molecular mechanisms controlling aggregation, the structure of aggregates (oligomeric or fibrillar), and the interactions with cell membranes. Model membranes consist of mono- or bilayers of lipids that can be placed in contact with proteins of biological interest, such as the amyloid proteins. The monolayer model membranes are obtained by depositing at the water-air interface bidimensional molecular films composed of phospholipids, gangliosides, and cholesterol, with and without proteins (Languimur technique) $[126,127]$. On these systems, thermodynamic measurements of compression at constant temperature (isotherms) provide useful information on the lipid mosaic phase (solid, liquid, or gaseous) and its modification due to the presence of proteins. Liposomes are vesicular structures, composed of bilayer model membranes. Mono- or bilayer membranes can be deposited onto solid substrates and studied with imaging techniques, such as Energy-Filtered TEM (EFTEM) or AFM, at nanometric resolution [128, 129]. In liposomes, which are suspended in a water solution, the conformation of proteins interacting or not with the lipid bilayer can be also investigated by Circular Dichroism Spectroscopy (CDS) $[119,130]$.

6.2. Imaging Techniques. EFTEM represents a powerful tool in the study of biological and nonbiological materials. The use of fast electrons (80-120 KeV) and magnetic lenses allows creating images of thin samples with horizontal resolution in the order of $0.4 \mathrm{~nm}$. This is due to the small wavelength associated to electrons of this energy (about $0.005 \mathrm{~nm}$ ). Using this technique, it is possible to investigate the quaternary structure and aggregation of misfolded proteins and their interaction with model membranes. In this case the image formation is obtained by negative staining with heavy metals such as tungsten and uranium. This technique allows obtaining horizontal resolution in the order of $1 \mathrm{~nm}$. However, using microscopes equipped with energy filters, it is possible to improve the image quality and increase contrast even in unstained samples and perform spectroscopic studies of the transmitted electrons (Figure 2) [128, 131].

EFTEM can also be combined with immunolabeling techniques to identify proteins by using specific antibodies, conjugated with gold particles (Figure 3 ). This technique is particularly useful to investigate binding of amyloid proteins to lipid membranes [119].

In AFM, the surface of the sample to be analyzed is scanned by a very sharp tip. The interaction forces occurring between the tip and the atoms of the analyzed surface, in the order of nanonewtons, cause the deflection of the cantilever supporting the tip. Changes in the deflection of the cantilever, due to the morphology of the sample surface, are detected by the reflection of a laser beam. The microscope can operate in static or dynamic mode if the tip is at rest or oscillating vertically, respectively. The structural organization of liposomes or Langmuir films can be imaged by this technique after deposition onto flat substrates of mica, with a resolution up to $1 \mathrm{~nm}$ horizontally and $0.1 \mathrm{~nm}$ vertically. Morphologic changes induced in model membranes by the incorporation of pore-forming proteins, such as gramicidin A [132], or LR components, such as gangliosides [133], can be analyzed with this technique. 


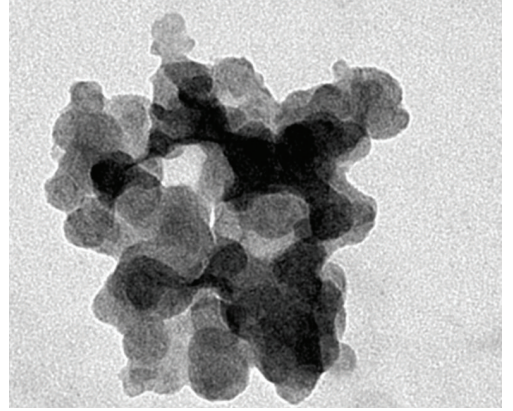

(a)

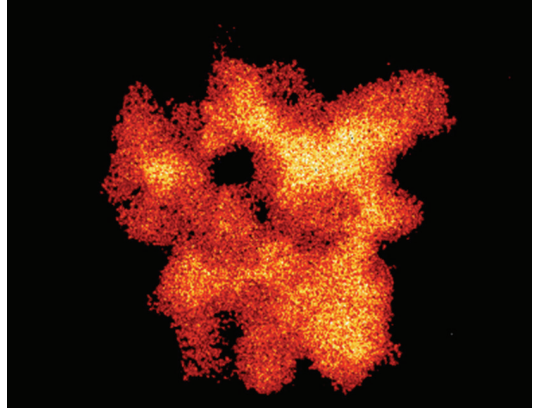

(b)

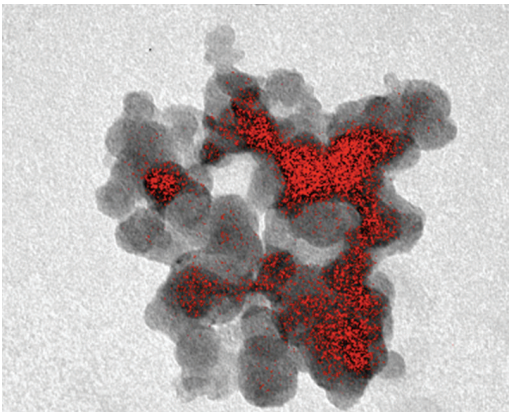

(c)

FIgURE 2: EFTEM micrograph of a cluster of liposomes (a). The ESI maps show a higher (b) and a lower (c) concentration of Cs entrapped in liposomes. Reproduced with permission from [131].

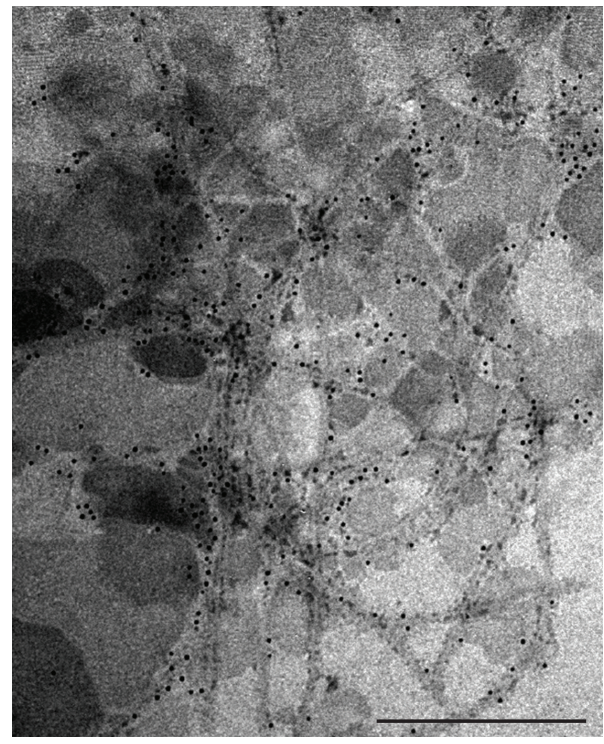

(a)

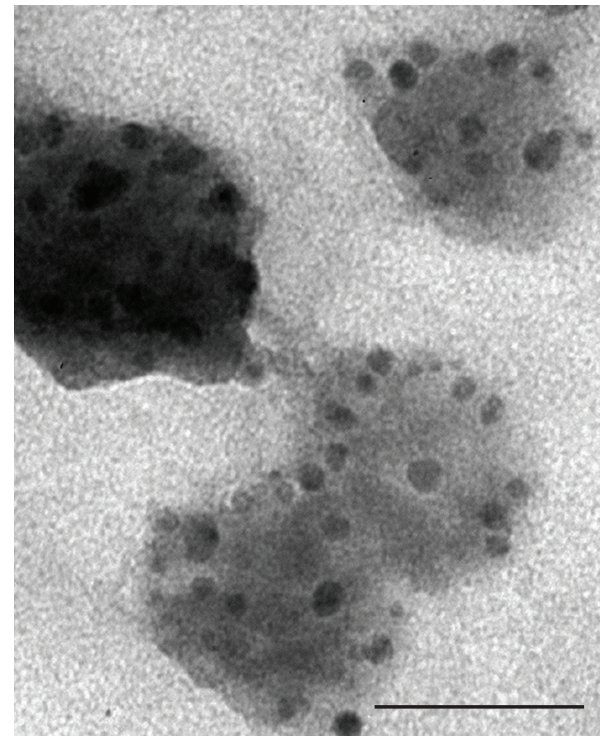

(b)

FIGURE 3: Immunogold EFTEM micrographs of sCT in mature fibres ((a) bar $=200 \mathrm{~nm})$ and liposomes, where sCT is inserted in the lipid bilayer $((\mathrm{b})$ bar $=50 \mathrm{~nm})$. Picture in $(\mathrm{b})$ was reproduced with permission from [119].

6.3. CDS. CDS can be considered a special type of UV absorption spectroscopy and consists in the measure of the difference in the absorbance of left- and right-handed polarized light by optically active molecules, detected in a selected frequency range. This signal depends on the wavelength of the incident light. A dichroic spectrum can be obtained illuminating an optical active sample by light of increasing wavelength. The optical activity of a molecule depends, in the absence of magnetic field, on its chirality: in general, a molecule having an asymmetric charge distribution interacts in a different way with electromagnetic waves characterized by opposite circular polarization.

This type of spectroscopy is generally used to investigate the protein conformation and their change induced by the aggregation process or the interaction with model membranes $[119,132]$. In the region of the near UV $(250-$ $350 \mathrm{~nm}$ ), it is possible to obtain information about the tertiary structure of proteins. In this region the aromatic amino acid and the disulfide bonds are excited, giving rise to a dichroic signal depending on the overall three-dimensional structure of the protein. An important application of this technique is to analyze the "folded" state of the proteins; if this is "molten globule" or the protein is incorrectly folded, the near UV spectrum is practically flat. The near UV spectrum is sensitive to small variations of the tertiary structure, due to the interaction of the proteins with other molecules, such as lipids. In the far UV region (190-250 nm), the secondary structure of the proteins can be studied. In this region the chromophore, which is the protein component excited by the incident light, is the peptidic bond. A typical dichroic spectrum for each type of secondary structure exists, and the spectrum of a protein conformed with several secondary structures is formed by the convolution of the base spectra. 


\section{LRs and htt}

Some observations suggest that LRs may be implicated in $\mathrm{HD}$ pathogenesis at different levels. From DNA microarray analysis conducted in striatal cells expressing wild-type or mutant htts, genes involved in cholesterol biosynthesis were found to be altered by mutant protein. Since in these cells mutant htt did not form aggregates or cause cell death, this pattern of gene expression may reflect early events in the pathogenetic mechanism [134]. Consistently, dysfunction in the cholesterol biosynthetic pathway was described in mice and cell culture models of HD [135]. In addition, abnormal expression of the genes encoding glycosyltransferases, an enzyme involved in the synthesis of gangliosides, were found in the striatum of the R6/1 transgenic mouse, an animal model of HD, and in postmortem caudate samples from human HD subjects [136]. These observations indicate a disruption in glycolipid metabolic pathways that may alter LR formation. Biochemical analysis of cell membranes from brains and primary neurons of wild-type and presymptomatic HD knockin mice showed that wild-type and mutant htt were recovered in LR-enriched membranes [137]. The association with LRs was stronger for mutant than wild-type htt. In addition, LR from HD mice had a higher content in glycogen synthase kinase 3-beta (GSK). Since GSK activation is involved in neuronal apoptosis, the authors speculate that accumulation of mutant htt and GSK in LRs may have a role in the mechanism of neurodegeneration in HD [137].

\section{LRs and $\alpha$-syn}

Although the mechanisms correlating $\alpha$-syn aggregates to PD pathogenesis remain unclear, there is substantial evidence that binding of $\alpha$-syn aggregates to lipid membranes is a relevant factor. Oligomeric $\alpha$-syn binds to model membranes inducing permeabilization of synthetic vesicles, which is considered a potentially cytotoxic event [138]. Dimeric aggregates of wild-type $\alpha$-syn and its mutants, A53T and A30P, seem to bind to and disrupt lipid membranes more easily than monomeric forms [139], indicating that oligomeric forms are likely to be the pathogenic species. However, even monomeric $\alpha$-syn can interact with model membranes, undergoing a conformational change from a random coil to an $\alpha$-helical structure, which may facilitate aggregation [140]. The lipid components seem to have a relevant role in the interaction between $\alpha$-syn and membranes. $\alpha$-syn binds to GM1 ganglioside, which are enriched in LRs. This bound is attributed to specific interaction between $\alpha$-syn and glycidic residues of GM1, such as sialic acid [141]. In addition, $\alpha$-syn colocalizes with markers of LRs in Hela cell cultures [142]. In the neuronal cells, $\alpha$-syn is localized in the synaptic terminals, as described above. LR disruption was found to abolish the synaptic localization of $\alpha$-syn and redistribute it to different cell compartments [142]. Furthermore, association with synaptic LRs is also impaired in the A30P mutation, suggesting that the physiological role of $\alpha$-syn, lost in the mutated protein, is mediated by LR interaction [142].

\section{LRs and PrP}

The role of LRs has been the object of considerable interest in prion infectivity. By using model membranes, it has been shown that recombinant forms of the PrPs bind to model LR membranes composed of phospholipids, cholesterol, and sphingomyelin, but not to zwitterionic PC lipids, an artificial model lacking LR components [143, 144]. Inhibitors of the synthesis of cholesterol, a major component of LRs, reduce prion formation in vitro $[145,146]$ and delay the progression of experimental infection [147]. A large body of evidence sustains that LRs are the site where conversion from PrPC to PrPSc takes place [148]. A crucial role has been detected for the PrPC glycosylphosphatidylinositol (GPI) anchor, a complex machinery that has several physiological roles, among which is the targeting of proteins to LRs. Through the GPI anchor, PrPC binds to cell membranes [149]. In absence of the GPI anchor, PrPC redistributes into non-raft regions of the plasma membrane, and the formation of PrPSc is reduced [150]. In addition, synthetic analogues of the GPI anchor [151] and its enzymatic modification [152] reduce the capacity of PrPSc to bind and replicate within neuronal cell lines or primary cortical neurons, suggesting that PrPSc conversion takes place in LR-like microenvironment, following targeting of PrPC to LRs. In vivo studies, however, have shown that the role of the GPI anchor is probably more complex than initially assumed. Enzymatic removal of the GPI anchor from PrPSc did not reduce prion infectivity [153], while, in scrapieinfected transgenic mice producing PrPC without a GPI anchor, a high amount of infectious PrPSc was produced, though in the absence of clinical symptoms [154]. However, when mice were engineered to express twofold more anchorless PrP, scrapie infection did induce a fatal disease [155].

\section{LRs and CT}

Calcitonin (CT), a 32-residue polypeptidic hormone secreted by the $\mathrm{C}$ cells of the thyroid gland, belongs to a family of structurally and functionally related regulatory hormones, which also includes amylin, adrenomedullin, and CT gene-related peptide. It plays an important role in $\mathrm{Ca}^{2+}$ regulation and bone metabolism. For its activity in reducing bone resorption, it is a therapeutic option in the treatment of osteoporosis. The amyloid nature of CT was unveiled when it was demonstrated that the protein is the principal component of the amyloid fibrils deposited in medullary carcinoma of the thyroid [156]. Later on, its ability to aggregate in vitro was studied as a factor limiting its efficacy as pharmaceutical agent [157-160]. The studies of Schubert and coworkers $[20,161]$ firstly showed that CT, in analogy with other amyloid proteins showing an aggregative behaviour, was toxic to cells in culture. These observations prompted investigators to use CT as a probe to study amyloid formation and neurotoxicity [162-165]. Salmon CT (sCT), which is neurotoxic as CT from other species $[20,159,166]$, is characterized by a slower aggregation rate [166], and this 

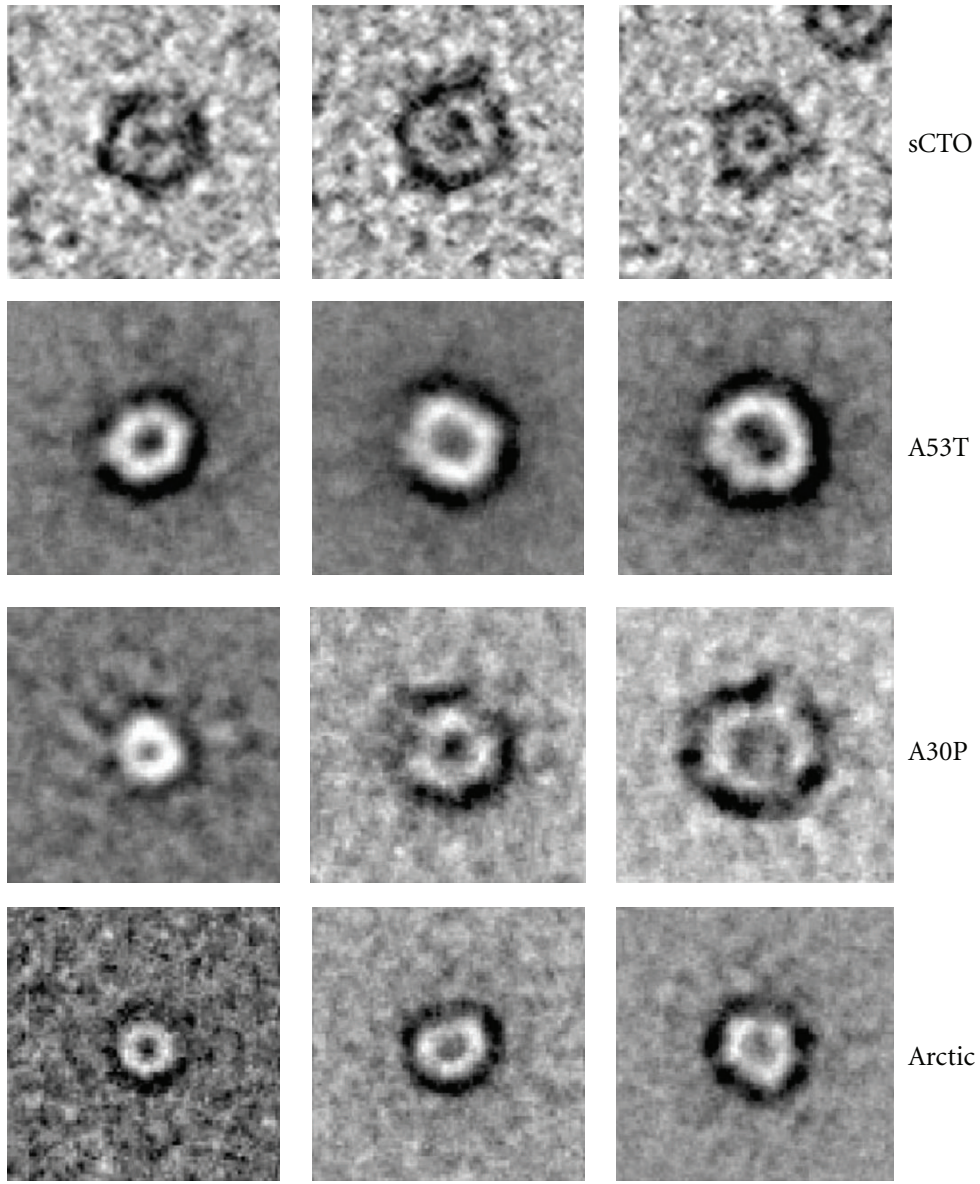

Figure 4: EFTEM of sCTOs. Annular sCTOs show remarkable morphologic similarities with amyloid pores of mutant $\alpha$-syn (A53T and $\mathrm{A} 30 \mathrm{P}$ ) and $\mathrm{A} \beta$ (Arctic). TEM images of $\alpha$-syn and $\mathrm{A} \beta$ were reproduced with permission from [169].

peculiarity is at the basis of its pharmacological use. We have studied the process of sCT oligomerization, focusing on the role of oxidation and time of aggregation [167, 168]. Recently, we showed that sCT oligomers (sCTOs) form $\mathrm{Ca}^{2+}$ permeable pores in liposomes [119], highly reminiscent of the ion channels formed by other amyloid proteins, such as A $\beta$ and $\alpha$-syn [169] (Figure 4). In addition, they damaged neuritic tree and synapses in hippocampal neurons, a behavior highly reminiscent of the effects induced by $\mathrm{A} \beta$ [170] (Figure 5).

We used sCT to investigate if a specific neuronal cell susceptibility to amyloid toxicity exists [170]. An issue that has seldom been addressed, in fact, is why misfolded proteins cause diseases so frequently in the CNS, in comparison to other systems or districts. Furthermore, several amyloid proteins, such as $\mathrm{CT}$, are toxic to neuronal cells despite the fact that they are formed outside the CNS. An exception could be represented by amylin, an amyloid protein belonging to CT family. This amyloid protein is considered as a possible pathogenetic species in the development of diabetes, supposedly by damaging pancreatic beta cells, thus exerting a cytotoxic effect outside the brain [171]. If one considers, however, that pancreatic $\beta$ cells share the same histogenesis of neuronal cells, being neural crest-derived neuroendocrine cells, type I diabetes would not represent an exception. The reasons for this peculiar vulnerability are presently unknown, but several hypotheses may be formulated, which are not mutually exclusive. (1) Neurons may provide a particularly suitable environment for protein misfolding processes, or be more prone to dysfunctions of the machinery deputed to misfolded protein removal. (2) The abundant presence of calcium-permeable ion channels, activated by amyloid proteins, may render $\mathrm{Ca}^{2+}$ dysregulation a much more probable event in neurons than in other cell types. (3) Neuronal cells may be more sensitive to the toxic potential of amyloid proteins, a likely event due to the dramatic effects induced by $\mathrm{Ca}^{2+}$ dysregulation, as discussed above. (4) Finally, it may be speculated that neuronal cell membrane, due to its intrinsic characteristics, may be more prone to pore formation by oligomers. To address the latter hypothesis, we compared sCTO toxicity in mature, 14-day in vitro (DIV) or immature, $6 \mathrm{DIV}$, hippocampal neurons to that of cultured cells of different histogenesis: MG63 osteoblasts, NIH-3T3 fibroblasts (two immortalized cell lines), and primary astrocytic cultures from rat fetal brain [170]. 


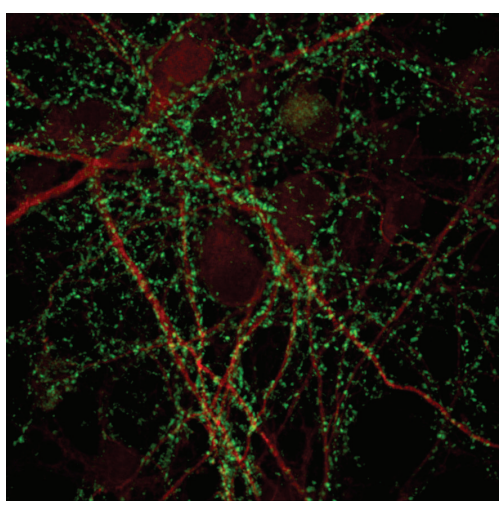

Control

(a)

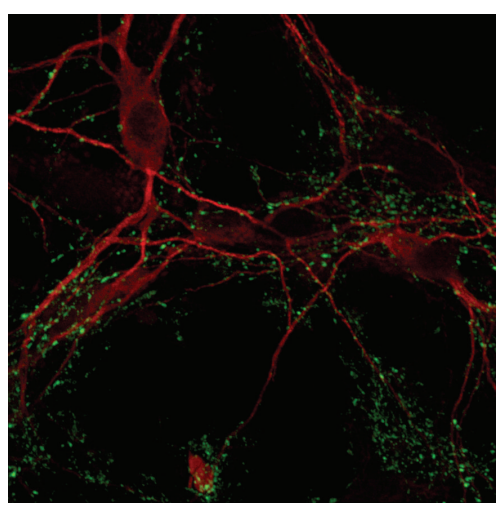

$\mathrm{A} \beta$

(b)

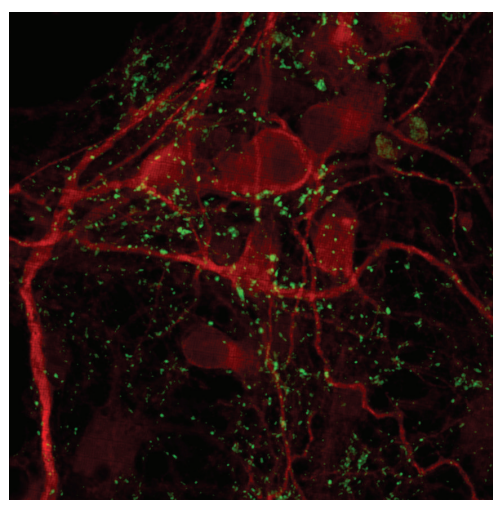

sCTO

(c)

Figure 5: sCTOs and $\mathrm{A} \beta$ oligomers similarly damage the neuritic tree and synapses in mature hippocampal neurons. After sCTO or $\mathrm{A} \beta$ treatments, the extension of the dendritic tree, immunolabeled for microtubule-associated protein 2 (red fluorescence), is evidently reduced, while the number of synapses, immunolabeled for synaptophysin (green fluorescence), is decreased.

Among the tested cell types, only mature hippocampal neurons responded to sCTOs with an intense and sustained rise in intracellular $\mathrm{Ca}^{2+}$ (Figure 6(a)) and an evident increase in apoptosis. This increase could be due to leakage of intracellular $\mathrm{Ca}^{2+}$ stores or sCTO-dependent stimulation of preexisting $\mathrm{Ca}^{2+}$ channels, as previously proposed and discussed above. The use of thapsigargin, a specific sarcoplasmic/endoplasmic reticulum $\mathrm{Ca}^{2+}$ ATPase pump inhibitor, which depletes intracellular $\mathrm{Ca}^{2+}$ stores, showed that sCTOinduced $\mathrm{Ca}^{2+}$ rise was mostly due to an extracellular influx (Figure 6(b)). We then considered the activity of NMDA receptor, which, among glutamate receptors, is the one that has most frequently been considered to be involved in the toxicity of amyloid proteins, as already discussed. MK801, a specific NMDA receptor blocker, poorly affected sCTOinduced $\mathrm{Ca}^{2+}$ entry. Furthermore, pretreatment with an antibody against the subunit 1 of NMDA receptor (NR1), used to mask possible sites of interactions between sCTOs and the NMDA receptor, again failed to inhibit $\mathrm{Ca}^{2+}$ entry (Figure 6(b)). Thus, the different behavior of cell types to sCTO, in terms of $\mathrm{Ca}^{2+}$ rise, was conceivably unrelated to an activation of preexisting $\mathrm{Ca}^{2+}$ channels and pointed to the formation of calcium-permeable amyloid pores by CT oligomers. We reasoned that the neuronal plasma membrane has other distinctive characteristics, compared to other cell types, such as, for example, a rich content in LRs. This hypothesis was confirmed by our results, where mature neuronal cells showed a much more elevated content in LRs of the other cells types examined (Figure 6(c)). It has also been demonstrated that LRs increase in the plasma membrane during in vitro maturation in hippocampal neurons [172]. This could explain why immature neurons were insensitive to sCTO toxicity. Thus, content in LRs higher than the other cell types could render neurons more vulnerable to amyloid toxicity. To further corroborate this hypothesis, we manipulated LRs in mature neuronal cells in the attempt of modifying sCTO-induced intracellular $\mathrm{Ca}^{2+}$ entry. Pretreatment of neurons with an antibody against GM1, a ganglioside particularly abundant in LRs, completely suppressed sCTO-driven $\mathrm{Ca}^{2+}$ rise, without altering NMDA receptor activity (Figure 6(b)). Furthermore, LR disruption obtained by neuraminidase (NAA), which removes sialic acid from gangliosides, inhibited $\mathrm{Ca}^{2+}$ rise and protected against sCTO neurotoxicity, probably modifying the plasma membrane area susceptible to the insertion of the pore-like structures (Figure $6(\mathrm{~d})$ ). These results strongly support the conclusion that the intense and protracted $\mathrm{Ca}^{2+}$ dysregulation observed after sCTOs treatment is reliably due to the pore formation in a particularly suitable environment, that is, the LR-rich neuronal plasma membrane.

\section{Conclusions}

LRs are crucial sites in the cell membrane, where pivotal events in the physiology of the cell take place. However, they may also represent areas of fragility of the cell membrane, providing a way into potential cell hosts, such as pathogens and misfolded proteins. The high content in LRs of mature neuronal plasma membrane may render these cells particularly vulnerable to the cytotoxic attack of amyloid proteins and represent one of the reasons for the high vulnerability of CNS to misfolded protein diseases. 


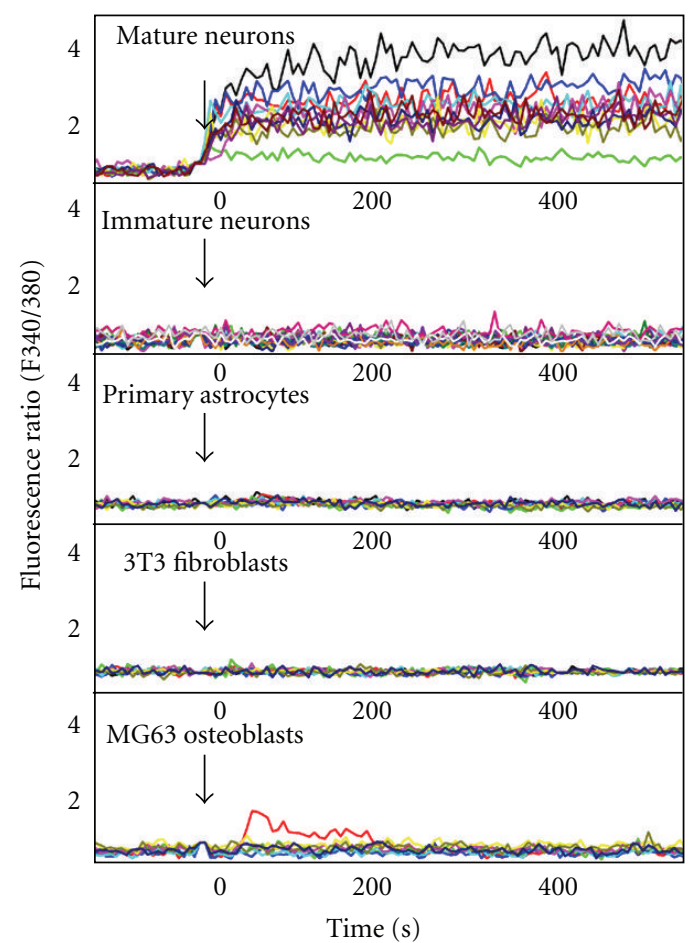

(a)

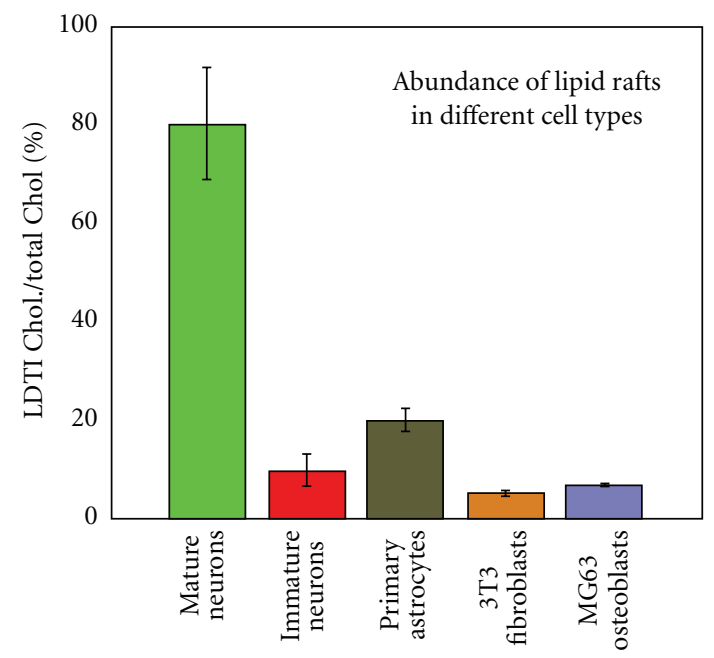

(c)

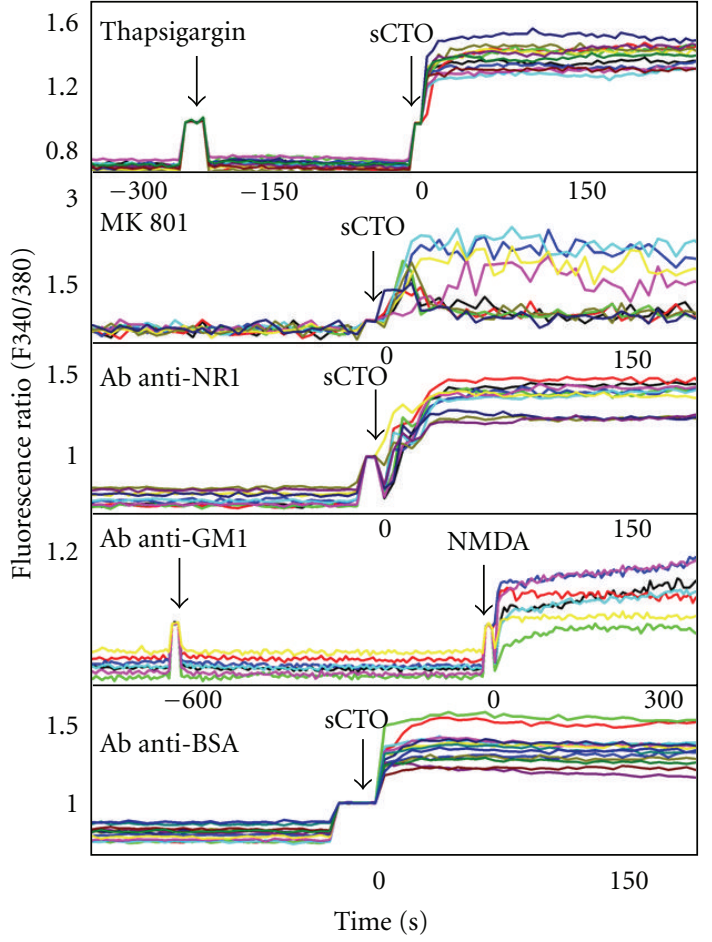

(b)

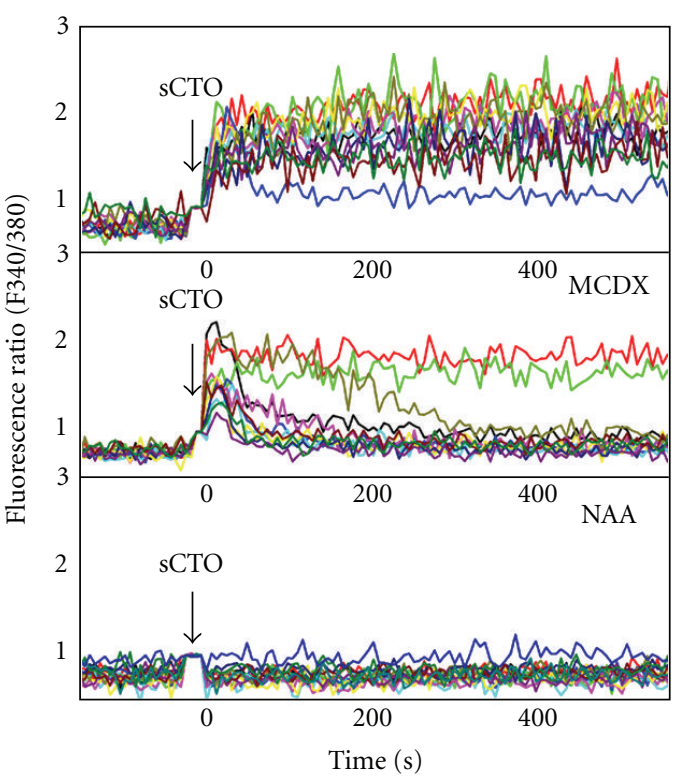

(d)

FIgURE 6: (a) sCTO induces increase in intracellular $\mathrm{Ca}^{2+}$ levels in mature hippocampal neurons, but not in immature neurons, primary astrocytes, 3T3 fibroblasts, and MG3 osteoblasts. $\mathrm{Ca}^{2+}$ levels were evaluated by optical fluorimetric recordings with Fura-2AM. (b) Depletion of intracellular $\mathrm{Ca}^{2+}$ stores with thapsigargin did not affect sCTO-induced $\mathrm{Ca}^{2+}$ rise, suggesting that it was mostly due to an extracellular $\mathrm{Ca}^{2+}$ influx. MK801, a specific NMDA inhibitor, as well as antibodies against NR1, failed to affect sCTO-driven Ca ${ }^{2+}$ influx, suggesting that the NMDA receptor was not involved. On the contrary, pretreatment with an antibody against the ganglioside GM1, aimed at blocking LRs, completely abolished sCTOs-induced $\mathrm{Ca}^{2+}$ increase. Pretreatment with anti-BSA IgGs, an unrelated antibody, did not affect sCTO response. (c) Measure of the weight ratio between cholesterol in LRs (LDTI) and total cholesterol indicates that plasma membrane of mature hippocampal neurons have a much higher content in LRs than the other cell types. (d) Pretreatment of hippocampal neurons with NAA totally suppressed sCTO-induced $\mathrm{Ca}^{2+}$ increase. Reproduced with permission and partially modified from $[170]$. 


\section{Abbreviations}

AD: $\quad$ Alzheimer's disease

A $\beta$ : $\quad$ Amyloid $\beta$

AFM: Atomic force microscopy

CT: Calcitonin

CDS: Circular dichroism spectroscopy

DIV: Day in vitro

ER: Endoplasmic reticulum

EFTEM: Energy filtered TEM

GSK: Glycogen synthase kinase 3-beta

GPI: Glycosylphosphatidylinositol

htt: Huntingtin

HD: Huntington's disease

LDTI: Low-density, triton-insoluble

LBs: Lewy bodies

LRs: Lipid rafts

LTD: Long-term depression

LTP: Long-term potentiation

NAA: Neuraminidase

NR1: $\quad$ NMDA receptor subunit 1

NMDA: N-methyl-D-aspartate

PD: Parkinson's disease

PrP: $\quad$ Prion protein

RyR: Ryanodine

sCTOs: sCT oligomers

sCT: $\quad$ Salmon CT

TSEs: Transmissible spongiform encephalopathies

TEM: Transmission electron microscopy

$\alpha$-syn: $\alpha$-synuclein.

\section{Acknowledgment}

The authors wish to thank Tamara C. Petrucci and Luisa Minghetti for helpful comments on the manuscript.

\section{References}

[1] D. A. Brown and J. K. Rose, "Sorting of GPI-anchored proteins to glycolipid-enriched membrane subdomains during transport to the apical cell surface," Cell, vol. 68, no. 3, pp. 533-544, 1992.

[2] M. Edidin, "The state of lipid rafts: from model membranes to cells," Annual Review of Biophysics and Biomolecular Structure, vol. 32, pp. 257-283, 2003.

[3] S. Munro, "Lipid rafts: elusive or illusive?" Cell, vol. 115, no. 4, pp. 377-388, 2003.

[4] L. J. Pike, "Rafts defined: a report on the Keystone symposium on lipid rafts and cell function," Journal of Lipid Research, vol. 47, no. 7, pp. 1597-1598, 2006.

[5] S. Mañes, G. Del Real, and C. Martínez-A, "Pathogens: raft hijackers," Nature Reviews Immunology, vol. 3, no. 7, pp. 557$568,2003$.

[6] N. Reig and F. G. van der Goot, "About lipids and toxins," FEBS Letters, vol. 580, no. 23, pp. 5572-5579, 2006.

[7] G. G. Glenner and C. W. Wong, "Alzheimer's disease: initial report of the purification and characterization of a novel cerebrovascular amyloid protein," Biochemical and Biophysical Research Communications, vol. 120, no. 3, pp. 885-890, 1984.
[8] G. G. Glenner and C. W. Wong, “Alzheimer's disease and Down's syndrome: sharing of a unique cerebrovascular amyloid fibril protein," Biochemical and Biophysical Research Communications, vol. 122, no. 3, pp. 1131-1135, 1984.

[9] C. L. Masters, G. Simms, and N. A. Weinman, "Amyloid plaque core protein in Alzheimer disease and Down syndrome," Proceedings of the National Academy of Sciences of the United States of America, vol. 82, no. 12, pp. 4245-4249, 1985.

[10] S. J. DeArmond, M. P. McKinley, and R. A. Barry, "Identification of prion amyloid filaments in scrapieinfected brain,” Cell, vol. 41, no. 1, pp. 221-235, 1985.

[11] S. B. Prusiner, "Novel proteinaceous infectious particles cause scrapie," Science, vol. 216, no. 4542, pp. 136-144, 1982.

[12] B. A. Yankner, A. Caceres, and L. K. Duffy, "Nerve growth factor potentiates the neurotoxicity of $\beta$ amyloid," Proceedings of the National Academy of Sciences of the United States of America, vol. 87, no. 22, pp. 9020-9023, 1990.

[13] K. Bettens, K. Sleegers, and C. Van Broeckhoven, "Current status on alzheimer disease molecular genetics: from past, to present, to future," Human Molecular Genetics, vol. 19, no. 1, pp. R4-R11, 2010.

[14] D. J. Selkoe, "The molecular pathology of Alzheimer's disease," Neuron, vol. 6, no. 4, pp. 487-498, 1991.

[15] J. A. Hardy and G. A. Higgins, "Alzheimer's disease: the amyloid cascade hypothesis," Science, vol. 256, no. 5054, pp. 184-185, 1992.

[16] O. Philipson, A. Lord, A. Gumucio, P. O'Callaghan, L. Lannfelt, and L. N. G. Nilsson, "Animal models of amyloid$\beta$-related pathologies in Alzheimer's disease," FEBS Journal, vol. 277, no. 6, pp. 1389-1409, 2010.

[17] K. H. Ashe and K. R. Zahs, "Probing the biology of Alzheimer's disease in mice," Neuron, vol. 66, no. 5, pp. 631-645, 2010.

[18] M. E. MacDonald, C. M. Ambrose, M. P. Duyao et al., "A novel gene containing a trinucleotide repeat that is expanded and unstable on Huntington's disease chromosomes. The Huntington's Disease Collaborative Research Group," Cell, vol. 72, no. 6, pp. 971-983, 1993.

[19] M. G. Spillantini, R. A. Crowther, R. Jakes, M. Hasegawa, and M. Goedert, “ $\alpha$-Synuclein in filamentous inclusions of Lewy bodies from Parkinson's disease and dementia with Lewy bodies," Proceedings of the National Academy of Sciences of the United States of America, vol. 95, no. 11, pp. 6469-6473, 1998.

[20] D. Schubert, C. Behl, R. Lesley et al., "Amyloid peptides are toxic via a common oxidative mechanism," Proceedings of the National Academy of Sciences of the United States of America, vol. 92, no. 6, pp. 1989-1993, 1995.

[21] M. P. Lambert, A. K. Barlow, B. A. Chromy et al., "Diffusible, nonfibrillar ligands derived from $\mathrm{A} \beta$ are potent central nervous system neurotoxins," Proceedings of the National Academy of Sciences of the United States of America, vol. 95, no. 11, pp. 6448-6453, 1998.

[22] D. M. Walsh and D. J. Selkoe, "Oligomers in the brain: the emerging role of soluble protein aggregates in neurodegeneration," Protein and Peptide Letters, vol. 11, no. 3, pp. 213-228, 2004.

[23] R. D. Terry, E. Masliah, D. P. Salmon et al., "Physical basis of cognitive alterations in Alzheimer's disease: synapse loss is the major correlate of cognitive impairment," Annals of Neurology, vol. 30, no. 4, pp. 572-580, 1991. 
[24] S. T. DeKosky and S. W. Scheff, "Synapse loss in frontal cortex biopsies in Alzheimer's disease: correlation with cognitive severity," Annals of Neurology, vol. 27, no. 5, pp. 457-464, 1990.

[25] D. M. Walsh, I. Klyubin, J. V. Fadeeva et al., "Naturally secreted oligomers of amyloid $\beta$ protein potently inhibit hippocampal long-term potentiation in vivo," Nature, vol. 416, no. 6880, pp. 535-539, 2002.

[26] R. Kayed, E. Head, J. L. Thompson et al., "Common structure of soluble amyloid oligomers implies common mechanism of pathogenesis," Science, vol. 300, no. 5618, pp. 486-489, 2003.

[27] M. Bucciantini, E. Giannoni, F. Chiti et al., "Inherent toxicity of aggregates implies a common mechanism for protein misfolding diseases," Nature, vol. 416, no. 6880, pp. 507-511, 2002.

[28] A. Quist, I. Doudevski, H. Lin et al., "Amyloid ion channels: a common structural link for protein-misfolding disease," Proceedings of the National Academy of Sciences of the United States of America, vol. 102, no. 30, pp. 10427-10432, 2005.

[29] N. Arispe, H. B. Pollard, and E. Rojas, "Giant multilevel cation channels formed by Alzheimer disease amyloid $\beta$-protein $[\mathrm{A} \beta \mathrm{P}-(1-40)]$ in bilayer membranes," Proceedings of the National Academy of Sciences of the United States of America, vol. 90, no. 22, pp. 10573-10577, 1993.

[30] A. Demuro, E. Mina, R. Kayed, S. C. Milton, I. Parker, and C. G. Glabe, "Calcium dysregulation and membrane disruption as a ubiquitous neurotoxic mechanism of soluble amyloid oligomers," Journal of Biological Chemistry, vol. 280, no. 17, pp. 17294-17300, 2005.

[31] J. Laurén, D. A. Gimbel, H. B. Nygaard, J. W. Gilbert, and S. M. Strittmatter, "Cellular prion protein mediates impairment of synaptic plasticity by amyloid- $\beta$ oligomers," Nature, vol. 457, no. 7233, pp. 1128-1132, 2009.

[32] H. W. Kessels, L. N. Nguyen, S. Nabavi, and R. Malinow, "The prion protein as a receptor for amyloid-beta," Nature, vol. 466, no. 7308, pp. E3-E4, 2010.

[33] A. M. Calella, M. Farinelli, M. Nuvolone et al., "Prion protein and Abeta-related synaptic toxicity impairment," EMBO Molecular Medicine, vol. 2, no. 8, pp. 306-314, 2010.

[34] C. Balducci, M. Beeg, M. Stravalaci et al., "Synthetic amyloid$\beta$ oligomers impair long-term memory independently of cellular prion protein," Proceedings of the National Academy of Sciences of the United States of America, vol. 107, no. 5, pp. 2295-2300, 2010.

[35] I. Benilova and B. De Strooper, "Prion protein in Alzheimer's pathogenesis: a hot and controversial issue," $E M B O$ Molecular Medicine, vol. 2, no. 8, pp. 289-290, 2010.

[36] L. Goldschmidt, P. K. Teng, R. Riek, and D. Eisenberg, "Identifying the amylome, proteins capable of forming amyloid-like fibrils," Proceedings of the National Academy of Sciences of the United States of America, vol. 107, no. 8, pp. 3487-3492, 2010.

[37] R. Kayed, A. Pensalfini, L. Margol et al., "Annular protofibrils area structurally and functionally distinct type of amyloid oligomer," Journal of Biological Chemistry, vol. 284, no. 7, pp. 4230-4237, 2009.

[38] R. Kayed and C. G. Glabe, "Conformation-dependent anti-amyloid oligomer antibodies," Methods in Enzymology, vol. 413, pp. 326-344, 2006.

[39] L. M. Bekris, I. F. Mata, and C. P. Zabetian, "The genetics of Parkinson disease," Journal of Geriatric Psychiatry and Neurology, vol. 23, no. 4, pp. 228-242, 2010.
[40] L. C. Serpell, J. Berriman, R. Jakes, M. Goedert, and R. A. Crowther, "Fiber diffraction of synthetic $\alpha$-synuclein filaments shows amyloid-like cross- $\beta$ conformation," Proceedings of the National Academy of Sciences of the United States of America, vol. 97, no. 9, pp. 4897-4902, 2000.

[41] K. A. Conway, J. D. Harper, and P. T. Lansbury Jr., "Fibrils formed in vitro from $\alpha$-synuclein and two mutant forms linked to Parkinson's disease are typical amyloid," Biochemistry, vol. 39, no. 10, pp. 2552-2563, 2000.

[42] E. A. Greenbaum, C. L. Graves, A. J. Mishizen-Eberz et al., "The E46K mutation in $\alpha$-synuclein increases amyloid fibril formation," Journal of Biological Chemistry, vol. 280, no. 9, pp. 7800-7807, 2005.

[43] H. A. Lashuel, B. M. Petre, J. Wall et al., " $\alpha$-synuclein, especially the parkinson's disease-associated mutants, forms pore-like annular and tubular protofibrils," Journal of Molecular Biology, vol. 322, no. 5, pp. 1089-1102, 2002.

[44] M. J. Volles, S. J. Lee, J. C. Rochet et al., "Vesicle permeabilization by protofibrillar $\alpha$-synuclein: implications for the pathogenesis and treatment of Parkinson's disease," Biochemistry, vol. 40, no. 26, pp. 7812-7819, 2001.

[45] K. M. Danzer, D. Haasen, A. R. Karow et al., "Different species of $\alpha$-synuclein oligomers induce calcium influx and seeding," Journal of Neuroscience, vol. 27, no. 34, pp. 9220-9232, 2007.

[46] E. A. Waxman and B. I. Giasson, "Molecular mechanisms of $\alpha$-synuclein neurodegeneration," Biochimica et Biophysica Acta, vol. 1792, no. 7, pp. 616-624, 2009.

[47] D. P. Karpinar, M. B.G. Balija, S. Kügler et al., "Pre-fibrillar $\alpha$-synuclein variants with impaired $\beta$-structure increase neurotoxicity in parkinson's disease models," EMBO Journal, vol. 28, no. 20, pp. 3256-3268, 2009.

[48] N. Cavallarin, M. Vicario, and A. Negro, "The role of phosphorylation in synucleinopathies: focus on Parkinson's disease," CNS and Neurological Disorders, vol. 9, no. 4, pp. 471-481, 2010.

[49] E. Scherzinger, R. Lurz, M. Turmaine et al., "Huntingtinencoded polyglutamine expansions form amyloid-like protein aggregates in vitro and in vivo," Cell, vol. 90, no. 3, pp. 549-558, 1997.

[50] I. Bezprozvanny and M. R. Hayden, "Deranged neuronal calcium signaling and Huntington disease," Biochemical and Biophysical Research Communications, vol. 322, no. 4, pp. 1310-1317, 2004.

[51] T. S. Tang, E. Slow, V. Lupu et al., "Disturbed $\mathrm{Ca}^{2+}$ signalling and apoptosis of medium spiny neurons in Huntington's disease," Proceedings of the National Academy of Sciences of the United States of America, vol. 102, no. 7, pp. 2602-2607, 2005.

[52] S. Simoneau, H. Rezaei, N. Salès et al., "In vitro and in vivo neurotoxicity of prion protein oligomers.," PLoS Pathogens, vol. 3, no. 8, article e125, 2007.

[53] J. R. Silveira, G. J. Raymond, A. G. Hughson et al., "The most infectious prion protein particles," Nature, vol. 437, no. 7056, pp. 257-261, 2005.

[54] B. Caughey and P. T. Lansbury, "Protofibrils, pores, fibrils, and neurodegeneration: separating the responsible protein aggregates from the innocent bystanders," Annual Review of Neuroscience, vol. 26, pp. 267-298, 2003.

[55] C. A. Davies, D. M. A. Mann, P. Q. Sumpter, and P. O. Yates, "A quantitative morphometric analysis of the neuronal and synaptic content of the frontal and temporal cortex in patients with Alzheimer's disease," Journal of the Neurological Sciences, vol. 78, no. 2, pp. 151-164, 1987. 
[56] C. I. Sze, J. C. Troncoso, C. Kawas, P. Mouton, D. L. Price, and L. J. Martin, "Loss of the presynaptic vesicle protein synaptophysin in hippocampus correlates with cognitive decline in Alzheimer disease," Journal of Neuropathology and Experimental Neurology, vol. 56, no. 8, pp. 933-944, 1997.

[57] J. P. Cleary, D. M. Walsh, J. J. Hofmeister et al., "Natural oligomers of the amyloid- $\beta$ protein specifically disrupt cognitive function," Nature Neuroscience, vol. 8, no. 1, pp. 79-84, 2005.

[58] D. J. Selkoe, "Soluble oligomers of the amyloid $\beta$-protein impair synaptic plasticity and behavior," Behavioural Brain Research, vol. 192, no. 1, pp. 106-113, 2008.

[59] G. M. Shankar, S. Li, T. H. Mehta et al., "Amyloid- $\beta$ protein dimers isolated directly from Alzheimer's brains impair synaptic plasticity and memory," Nature Medicine, vol. 14, no. 8 , pp. 837-842, 2008.

[60] I. G. McKeith and U. P. Mosimann, "Dementia with Lewy bodies and Parkinson's disease," Parkinsonism and Related Disorders, vol. 10, no. 1, pp. S15-S18, 2004.

[61] D. Aarsland, M. K. Beyer, and M. W. Kurz, "Dementia in Parkinson's disease," Current Opinion in Neurology, vol. 21, no. 6, pp. 676-682, 2008.

[62] D. F. Clayton and J. M. George, "Synucleins in synaptic plasticity and neurodegenerative disorders," Journal of Neuroscience Research, vol. 58, no. 1, pp. 120-129, 1999.

[63] D. D. Murphy, S. M. Rueter, J. Q. Trojanowski, and V. M. Y. Lee, "Synucleins are developmentally expressed, and $\alpha$ synuclein regulates the size of the presynaptic vesicular pool in primary hippocampal neurons," Journal of Neuroscience, vol. 20, no. 9, pp. 3214-3220, 2000.

[64] S. Chandra, G. Gallardo, R. Fernández-Chacón, O. M. Schlüter, and T. C. Südhof, " $\alpha$-synuclein cooperates with CSP $\alpha$ in preventing neurodegeneration," Cell, vol. 123, no. 3, pp. 383-396, 2005.

[65] S. Bellani, V. L. Sousa, G. Ronzitti, F. Valtorta, J. Meldolesi, and E. Chieregatti, "The regulation of synaptic function by $\alpha$-synuclein," Communitative and Integrative Biology, vol. 3, no. 2, pp. 106-109, 2010.

[66] M. L. Kramer and W. J. Schulz-Schaeffer, "Presynaptic $\alpha$-synuclein aggregates, not Lewy bodies, cause neurodegeneration in dementia with lewy bodies," Journal of Neuroscience, vol. 27, no. 6, pp. 1405-1410, 2007.

[67] W. J. Schulz-Schaeffer, "The synaptic pathology of $\alpha$ synuclein aggregation in dementia with Lewy bodies, Parkinson's disease and Parkinson's disease dementia," Acta Neuropathologica, pp. 131-143, 2010.

[68] D. A. Scott, I. Tabarean, Y. Tang, A. Cartier, E. Masliah, and S. Roy, "A pathologic cascade leading to synaptic dysfunction in $\alpha$-synuclein-induced neurodegeneration," Journal of Neuroscience, vol. 30, no. 24, pp. 8083-8095, 2010.

[69] D. M. Cummings, A. J. Milnerwood, G. M. Dallérac, S. C. Vatsavayai, M. C. Hirst, and K. P. S. J. Murphy, "Abnormal cortical synaptic plasticity in a mouse model of Huntington's disease," Brain Research Bulletin, vol. 72, no. 2-3, pp. 103-107, 2007.

[70] J. Spampanato, X. Gu, X. W. Yang, and I. Mody, "Progressive synaptic pathology of motor cortical neurons in a BAC transgenic mouse model of Huntington's disease," Neuroscience, vol. 157, no. 3, pp. 606-620, 2008.

[71] J. L. Rozas, L. Gómez-Sánchez, C. Tomás-Zapico, J. J. Lucas, and R. Fernández-Chacón, "Presynaptic dysfunction in Huntington's disease," Biochemical Society Transactions, vol. 38, no. 2, pp. 488-492, 2010.
[72] C. Cepeda, R. S. Hurst, C. R. Calvert et al., "Transient and progressive electrophysiological alterations in the corticostriatal pathway in a mouse model of Huntington's disease," Journal of Neuroscience, vol. 23, no. 3, pp. 961-969, 2003.

[73] M. T. Usdin, P. F. Shelbourne, R. M. Myers, and D. V. Madison, "Impaired synaptic plasticity in mice carrying the Huntington's disease mutation," Human Molecular Genetics, vol. 8, no. 5, pp. 839-846, 1999.

[74] A. J. Milnerwood, D. M. Cummings, G. M. Dallérac et al., "Early development of aberrant synaptic plasticity in a mouse model of Huntington's disease," Human Molecular Genetics, vol. 15, no. 10, pp. 1690-1703, 2006.

[75] E. Romero, G. H. Cha, P. Verstreken et al., "Suppression of neurodegeneration and increased neurotransmission caused by expanded full-length huntingtin accumulating in the cytoplasm," Neuron, vol. 57, no. 1, pp. 27-40, 2008.

[76] T. Kitamoto, R. W. Shin, K. Doh-ura et al., "Abnormal isoform of prion proteins accumulates in the synaptic structures of the central nervous system in patients with Creutzfeldt-Jakob disease," American Journal of Pathology, vol. 140, no. 6, pp. 1285-1294, 1992.

[77] J. G. Fournier, F. Escaig-Haye, and V. Grigoriev, "Ultrastructural localization of prion proteins: physiological and pathological implications," Microscopy Research and Technique, vol. 50, no. 1, pp. 76-88, 2000.

[78] M. Jeffrey, W. G. Halliday, J. Bell et al., "Synapse loss associated with abnormal PrP precedes neuronal degeneration in the scrapie-infected murine hippocampus," Neuropathology and Applied Neurobiology, vol. 26, no. 1, pp. 41-54, 2000.

[79] C. Cunningham, R. Deacon, H. Wells et al., "Synaptic changes characterize early behavioural signs in the ME7 model of murine prion disease," European Journal of Neuroscience, vol. 17, no. 10, pp. 2147-2155, 2003.

[80] M. Fuhrmann, G. Mitteregger, H. Kretzschmar, and J. Herms, "Dendritic pathology in prion disease starts at the synaptic spine," Journal of Neuroscience, vol. 27, no. 23, pp. 6224-6233, 2007.

[81] B. C. Gray, Z. Siskova, V. H. Perry, and V. O'Connor, "Selective presynaptic degeneration in the synaptopathy associated with ME7-induced hippocampal pathology," Neurobiology of Disease, vol. 35, no. 1, pp. 63-74, 2009.

[82] Z. Sisková, D. J. Mahad, C. Pudney et al., "Morphological and functional abnormalities in mitochondria associated with synaptic degeneration in prion disease," American Journal of Pathology, vol. 177, no. 3, pp. 1411-1421, 2010.

[83] J. A. Moreno and G. R. Mallucci, "Dysfunction and recovery of synapses in prion disease: implications for neurodegeneration," Biochemical Society transactions, vol. 38, no. 2, pp. 482-487, 2010.

[84] G. R. Mallucci, M. D. White, M. Farmer et al., "Targeting cellular prion protein reverses early cognitive deficits and neurophysiological dysfunction in prion-infected mice," Neuron, vol. 53, no. 3, pp. 325-335, 2007.

[85] J. D. Harper and P. T. Lansbury Jr., "Models of amyloid seeding in Alzheimer's disease and scrapie: mechanistic truths and physiological consequences of the timedependent solubility of amyloid proteins," Annual Review of Biochemistry, vol. 66, pp. 385-407, 1997.

[86] M. D. Kane, W. J. Lipinski, M. J. Callahan et al., "Evidence for seeding of $\beta$-amyloid by intracerebral infusion of Alzheimer brain extracts in $\beta$-amyloid precursor protein-transgenic mice," Journal of Neuroscience, vol. 20, no. 10, pp. 3606-3611, 2000 . 
[87] M. Meyer-Luehmann, J. Coomaraswamy, T. Bolmont et al., "Exogenous induction of cerebral $\beta$-amyloidogenesis is governed bf agent and host," Science, vol. 313, no. 5794, pp. 1781-1784, 2006.

[88] X. Hu, S. L. Crick, G. Bu, C. Frieden, R. V. Pappu, and J. M. Lee, "Amyloid seeds formed by cellular uptake, concentration, and aggregation of the amyloid-beta peptide," Proceedings of the National Academy of Sciences of the United States of America, vol. 106, no. 48, pp. 20324-20329, 2010.

[89] S. J. Wood, J. Wypych, S. Steavenson, J. C. Louis, M. Citron, and A. L. Biere, " $\alpha$-synuclein fibrillogenesis is nucleationdependent: implications for the pathogenesis of Parkinson's disease," Journal of Biological Chemistry, vol. 274, no. 28, pp. 19509-19512, 1999.

[90] K. C. Luk, C. Song, P. O’Brien et al., "Exogenous $\alpha$-synuclein fibrils seed the formation of Lewy body-like intracellular inclusions in cultured cells," Proceedings of the National Academy of Sciences of the United States of America, vol. 106, no. 47, pp. 20051-20056, 2009.

[91] T. Nonaka, S. T. Watanabe, T. Iwatsubo, and M. Hasegawa, "Seeded aggregation and toxicity of $\alpha$-synuclein and tau: cellular models of neurodegenerative diseases," Journal of Biological Chemistry, vol. 285, no. 45, pp. 34885-34898, 2010.

[92] B. I. Giasson, V. M. Y. Lee, and J. Q. Trojanowski, "Interactions of amyloidogenic proteins," NeuroMolecular Medicine, vol. 4, no. 1-2, pp. 49-58, 2003.

[93] H. Yagi, E. Kusaka, K. Hongo, T. Mizobata, and Y. Kawata, "Amyloid fibril formation of $\alpha$-synuclein is accelerated by preformed amyloid seeds of other proteins: implications for the mechanism of transmissible conformational diseases," Journal of Biological Chemistry, vol. 280, no. 46, pp. 3860938616, 2005.

[94] A. Peim, P. Hortschansky, T. Christopeit, V. Schroeckh, W. Richter, and M. Fändrich, "Mutagenic exploration of the cross-seeding and fibrillation propensity of Alzheimer's $\beta$-amyloid peptide variants," Protein Science, vol. 15, no. 7, pp. 1801-1805, 2006.

[95] P. Desplats, H. J. Lee, E. J. Bae et al., "Inclusion formation and neuronal cell death through neuron-to-neuron transmission of $\alpha$-synuclein," Proceedings of the National Academy of Sciences of the United States of America, vol. 106, no. 31, pp. 13010-13015, 2009.

[96] J. Y. Li, E. Englund, J. L. Holton et al., "Lewy bodies in grafted neurons in subjects with Parkinson's disease suggest host-to-graft disease propagation," Nature Medicine, vol. 14, no. 5, pp. 501-503, 2008.

[97] J. H. Kordower, Y. Chu, R. A. Hauser, T. B. Freeman, and C. W. Olanow, "Lewy body-like pathology in long-term embryonic nigral transplants in Parkinson's disease," Nature Medicine, vol. 14, no. 5, pp. 504-506, 2008.

[98] B. Frost and M. I. Diamond, "Prion-like mechanisms in neurodegenerative diseases," Nature Reviews Neuroscience, vol. 11, no. 3, pp. 155-159, 2010.

[99] M. Goedert, F. Clavaguera, and M. Tolnay, "The propagation of prion-like protein inclusions in neurodegenerative diseases," Trends in Neurosciences, vol. 33, no. 7, pp. 317-325, 2010.

[100] H. Tu, O. Nelson, A. Bezprozvanny et al., "Presenilins form $\mathrm{ER} \mathrm{Ca}^{2+}$ leak channels, a function disrupted by familial Alzheimer's disease-linked mutations," Cell, vol. 126, no. 5, pp. 981-993, 2006.
[101] H. Zhang, S. Sun, A. Herreman, B. De Strooper, and I. Bezprozvanny, "Role of presenilins in neuronal calcium homeostasis," Journal of Neuroscience, vol. 30, no. 25, pp. 8566-8580, 2010.

[102] D. W. Choi, "Excitotoxic cell death," Journal of Neurobiology, vol. 23, no. 9, pp. 1261-1276, 1992.

[103] F. G. De Felice, P. T. Velasco, M. P. Lambert et al., “A $\beta$ oligomers induce neuronal oxidative stress through an $\mathrm{N}$-methyl-D-aspartate receptor-dependent mechanism that is blocked by the Alzheimer drug memantine," Journal of Biological Chemistry, vol. 282, no. 15, pp. 11590-11601, 2007.

[104] R. Mayeux, "Clinical practice. early alzheimer's disease," The New England Journal of Medicine, vol. 362, no. 23, pp. 2194-2201, 2010.

[105] B. L. Kelly and A. Ferreira, “ $\beta$-amyloid-induced dynamin 1 degradation is mediated by N-methyl-D-aspartate receptors in hippocampal neurons," Journal of Biological Chemistry, vol. 281, no. 38, pp. 28079-28089, 2006.

[106] A. MacManus, M. Ramsden, M. Murray, Z. Henderson, H. A. Pearson, and V. A. Campbell, "Enhancement of ${ }^{45} \mathrm{Ca}^{2+}$ influx and voltage-dependent $\mathrm{Ca}^{2+}$ channel activity by $\beta$-amyloid-(1-40) in rat cortical synaptosomes and cultured cortical neurons. Modulation by the proinflammatory cytokine interleukin-1 $\beta$," Journal of Biological Chemistry, vol. 275, no. 7, pp. 4713-4718, 2000.

[107] C. Rovira, N. Arbez, and J. Mariani, "A $\beta(25-35)$ and $A \beta(1-$ 40) act on different calcium channels in CA1 hippocampal neurons," Biochemical and Biophysical Research Communications, vol. 296, no. 5, pp. 1317-1321, 2002.

[108] J. J. Dougherty, J. Wu, and R. A. Nichols, " $\beta$-amyloid regulation of presynaptic nicotinic receptors in rat hippocampus and neocortex," Journal of Neuroscience, vol. 23, no. 17, pp. 6740-6747, 2003.

[109] T. K. Mehta, J. J. Dougherty, J. Wu, C. H. Choi, G. M. Khan, and R. A. Nichols, "Defining pre-synaptic nicotinic receptors regulated by beta amyloid in mouse cortex and hippocampus with receptor null mutants," Journal of Neurochemistry, vol. 109, no. 5, pp. 1452-1458, 2009.

[110] Q. Liu and B. Zhao, "Nicotine attenuates $\beta$-amyloid peptide-indueed neurotoxicity, free radical and calcium accumulation in hippocampal neuronal cultures," British Journal of Pharmacology, vol. 141, no. 4, pp. 746-754, 2004.

[111] W. Fu, H. Luo, S. Parthasarathy, and M. P. Mattson, "Catecholamines potentiate amyloid $\beta$-peptide neurotoxicity: involvement of oxidative stress, mitochondrial dysfunction, and perturbed calcium homeostasis," Neurobiology of Disease, vol. 5, no. 4, pp. 229-243, 1998.

[112] B. Ju Yeon and S. Yeon Hee, "Blockade of 5-HT(3) receptor with MDL 72222 and Y 25130 reduces beta-amyloid protein (25-35)-induced neurotoxicity in cultured rat cortical neurons," European Journal of Pharmacology, vol. 520, no. 1-3, pp. 12-21, 2005.

[113] G. E. Stutzmann, I. Smith, A. Caccamo, S. Oddo, F. M. LaFerla, and I. Parker, "Enhanced ryanodine receptor recruitment contributes to $\mathrm{Ca}^{2+}$ disruptions in young, adult, and aged Alzheimer's disease mice," Journal of Neuroscience, vol. 26, no. 19, pp. 5180-5189, 2006.

[114] A. Adamczyk and J. B. Strosznajder, "Alpha-synuclein potentiates $\mathrm{Ca}^{2+}$ influx through voltage-dependent $\mathrm{Ca}^{2+}$ channels," NeuroReport, vol. 17, no. 18, pp. 1883-1886, 2006. 
[115] M. M. Y. Fan, H. B. Fernandes, L. Y. J. Zhang, M. R. Hayden, and L. A. Raymond, "Altered NMDA receptor trafficking in a yeast artificial chromosome transgenic mouse model of Huntington's disease," Journal of Neuroscience, vol. 27, no. 14, pp. 3768-3779, 2007.

[116] H. Zhang, Q. Li, R. K. Graham, E. Slow, M. R. Hayden, and I. Bezprozvanny, "Full length mutant huntingtin is required for altered $\mathrm{Ca}^{2+}$ signaling and apoptosis of striatal neurons in the YAC mouse model of Huntington's disease," Neurobiology of Disease, vol. 31, no. 1, pp. 80-88, 2008.

[117] F. Pellistri, M. Bucciantini, A. Relini et al., "Nonspecific interaction of prefibrillar amyloid aggregates with glutamatergic receptors results in $\mathrm{Ca}^{2+}$ increase in primary neuronal cells," Journal of Biological Chemistry, vol. 283, no. 44, pp. 29950-29960, 2008.

[118] D. H. Cribbs, C. J. Pike, S. L. Weinstein, P. Velazquez, and C. W. Cotman, "All-D-enantiomers of $\beta$-amyloid exhibit similar biological properties to all-L- $\beta$-amyloids," Journal of Biological Chemistry, vol. 272, no. 11, pp. 7431-7436, 1997.

[119] M. Diociaiuti, L. Z. Polzi, L. Valvo, F. Malchiodi-Albedi, C. Bombelli, and M. C. Gaudiano, "Calcitonin forms oligomeric pore-like structures in lipid membranes," Biophysical Journal, vol. 91, no. 6, pp. 2275-2281, 2006.

[120] B. L. Kagan and J. Thundimadathil, "Amyloid peptide pores and the beta sheet conformation," Advances in Experimental Medicine and Biology, vol. 677, pp. 150-167, 2010.

[121] S. Inoue, "In situ $\mathrm{A} \beta$ pores in $\mathrm{AD}$ brain are cylindrical assembly of A $\beta$ protofilaments," Amyloid, vol. 15, no. 4, pp. 223-233, 2008.

[122] H. A. Lashuel and P. T. Lansbury Jr., "Are amyloid diseases caused by protein aggregates that mimic bacterial poreforming toxins?" Quarterly Reviews of Biophysics, vol. 39, no. 2, pp. 167-201, 2006.

[123] K. Simons and E. Ikonen, "Functional rafts in cell membranes," Nature, vol. 387, no. 6633, pp. 569-572, 1997.

[124] K. Simons and M. J. Gerl, "Revitalizing membrane rafts: new tools and insights," Nature Reviews Molecular Cell Biology, vol. 11, no. 10, pp. 688-699, 2010.

[125] M. Vestergaard, T. Hamada, and M. Takagi, "Using model membranes for the study of amyloid beta:lipid interactions and neurotoxicity," Biotechnology and Bioengineering, vol. 99, no. 4, pp. 753-763, 2008.

[126] R. E. Brown, "Sphingolipid organization in biomembranes: what physical studies of model membranes reveal," Journal of Cell Science, vol. 111, no. 1, pp. 1-9, 1998.

[127] R. Maget-Dana, “The monolayer tecnique: a potent tool for studying the interfaccial properties of antimicrobial and membrane-lytic peptides and their interaction with lipid membranes," Biochimica et Biophysica Acta, vol. 1462, no. 1-2, pp. 109-140, 1999.

[128] M. Diociaiuti, "Electron energy loss spectroscopy microanalysis and imaging in the transmission electron microscope: example of biological applications," Journal of Electron Spectroscopy and Related Phenomena, vol. 143, no. 2-3, pp. 189-203, 2005.

[129] E. I. Goksu, J. M. Vanegas, C. D. Blanchette, W. C. Lin, and M. L. Longo, "AFM for structure and dynamics of biomembranes," Biochimica et Biophysica Acta, vol. 1788, no. 1, pp. 254-266, 2009.

[130] F. Heitz and N. Van Mau, "Protein structural changes induced by their uptake at interfaces," Biochimica et Biophysica Acta, vol. 1597, no. 1, pp. 1-11, 2002.
[131] F. Bordi, C. Cametti, S. Sennato, and M. Diociaiuti, "Direct evidence of multicompartment aggregates in polyelectrolytecharged liposome complexes," Biophysical Journal, vol. 91, no. 4, pp. 1513-1520, 2006.

[132] M. Diociaiuti, F. Bordi, A. Motta et al., "Aggregation of gramicidin A in phospholipid Langmuir-Blodgett monolayers," Biophysical Journal, vol. 82, no. 6, pp. 3198-3206, 2002.

[133] M. Diociaiuti, I. Ruspantini, C. Giordani, F. Bordi, and P. Chistolini, "Distribution of GD3 in DPPC monolayers: a thermodynamic and atomic force microscopy combined study," Biophysical Journal, vol. 86, no. 1 I, pp. 321-328, 2004.

[134] S. Sipione, D. Rigamonti, M. Valenza et al., "Early transcriptional profiles in huntingtin-induced striatal cells by microarray analyses," Human Molecular Genetics, vol. 11, no. 17, pp. 1953-1965, 2002.

[135] M. Valenza, D. Rigamonti, D. Goffredo et al., "Dysfunction of the cholesterol biosynthetic pathway in Huntington's disease," Journal of Neuroscience, vol. 25, no. 43, pp. 9932-9939, 2005.

[136] P. A. Desplats, C. A. Denny, K. E. Kass et al., "Glycolipid and ganglioside metabolism imbalances in Huntington's disease," Neurobiology of Disease, vol. 27, no. 3, pp. 265-277, 2007.

[137] A. Valencia, P. B. Reeves, E. Sapp et al., "Mutant huntingtin and glycogen synthase kinase $3-\beta$ accumulate in neuronal lipid rafts of a presymptomatic knock-in mouse model of Huntington's disease," Journal of Neuroscience Research, vol. 88, no. 1, pp. 179-190, 2010.

[138] M. J. Volles and P. T. Lansbury Jr., "Vesicle permeabilization by protofibrillar $\alpha$-synuclein is sensitive to Parkinson's disease-linked mutations and occurs by a pore-like mechanism," Biochemistry, vol. 41, no. 14, pp. 4595-4602, 2002.

[139] E. Giannakis, J. Pacífico, D. P. Smith et al., "Dimeric structures of $\alpha$-synuclein bind preferentially to lipid membranes," Biochimica et Biophysica Acta - Biomembranes, vol. 1778, no. 4, pp. 1112-1119, 2008.

[140] D. Eliezer, E. Kutluay, R. Bussell, and G. Browne, "Conformational properties of $\alpha$-synuclein in its free and lipid-associated states," Journal of Molecular Biology, vol. 307, no. 4, pp. 1061-1073, 2001.

[141] Z. Martinez, M. Zhu, S. Han, and A. L. Fink, "GM1 specifically interacts with $\alpha$-synuclein and inhibits fibrillation," Biochemistry, vol. 46, no. 7, pp. 1868-1877, 2007.

[142] D. L. Fortin, M. D. Troyer, K. Nakamura, S. I. Kubo, M. D. Anthony, and R. H. Edwards, "Lipid rafts mediate the synaptic localization of $\alpha$-synuclein," Journal of Neuroscience, vol. 24, no. 30, pp. 6715-6723, 2004.

[143] N. Sanghera and T. J. T. Pinheiro, "Binding of prion protein to lipid membranes and implications for prion conversion," Journal of Molecular Biology, vol. 315, no. 5, pp. 1241-1256, 2002.

[144] J. Kazlauskaite, N. Sanghera, I. Sylvester, C. Vénien-Bryan, and T. J. T. Pinheiro, "Structural changes of the prion protein in lipid membranes leading to aggregation and fibrillization," Biochemistry, vol. 42, no. 11, pp. 3295-3304, 2003.

[145] R. Wilson, C. Bate, R. Boshuizen, A. Williams, and J. Brewer, "Squalestatin alters the intracellular trafficking of a neurotoxic prion peptide," BMC Neuroscience, vol. 8, article 99, 2007.

[146] C. Bate, M. Salmona, L. Diomede, and A. Williams, "Squalestatin cures prion-infected neurons and protects against prion neurotoxicity," Journal of Biological Chemistry, vol. 279, no. 15, pp. 14983-14990, 2004. 
[147] S. W. Fai Mok, K. M. Thelen, C. Riemer et al., "Simvastatin prolongs survival times in prion infections of the central nervous system," Biochemical and Biophysical Research Communications, vol. 348, no. 2, pp. 697-702, 2006.

[148] D. R. Taylor and N. M. Hooper, "The prion protein and lipid rafts," Molecular Membrane Biology, vol. 23, no. 1, pp. 89-99, 2006.

[149] M. G. Paulick and C. R. Bertozzi, "The glycosylphosphatidylinositol anchor: a complex membrane-anchoring structure for proteins," Biochemistry, vol. 47, no. 27, pp. 69917000, 2008.

[150] A. Taraboulos, M. Scott, A. Semenov, D. Avraham, L. Laszlo, and S. B. Prusiner, "Cholesterol depletion and modification of $\mathrm{COOH}$-terminal targeting sequence of the prion protein inhibit formation of the scrapie isoform," Journal of Cell Biology, vol. 129, no. 1, pp. 121-132, 1995.

[151] C. Bate, M. Tayebi, and A. Williams, "Glycosylphosphatidylinositol anchor analogues sequester cholesterol and reduce prion formation," Journal of Biological Chemistry, vol. 285, no. 29, pp. 22017-22026, 2010.

[152] C. Bate, M. Tayebi, and A. Williams, "The glycosylphosphatidylinositol anchor is a major determinant of prion binding and replication," The Biochemical Journal, vol. 428, no. 1, pp. 95-101, 2010.

[153] P. A. Lewis, F. Properzi, K. Prodromidou, A. R. Clarke, J. Collinge, and G. S. Jackson, "Removal of the glycosylphosphatidylinositol anchor from PrP by cathepsin D does not reduce prion infectivity," Biochemical Journal, vol. 395, no. 2, pp. 443-448, 2006.

[154] B. Chesebro, M. Trifilo, R. Race et al., "Medicine: anchorless prion protein results in infectious amyloid disease without clinical scrapie," Science, vol. 308, no. 5727, pp. 1435-1439, 2005.

[155] B. Chesebro, B. Race, K. Meade-White et al., "Fatal transmissible amyloid encephalopathy: a new type of prion disease associated with lack of prion protein membrane anchoring," PLoS Pathogens, vol. 6, no. 3, article e1000800, 2010.

[156] K. Sletten, P. Westermark, and J. B. Natvig, "Characterization of amyloid fibril proteins from medullary carcinoma of the thyroid," Journal of Experimental Medicine, vol. 143, no. 4, pp. 993-998, 1976.

[157] H. H. Bauer, M. Muller, J. Goette, H. P. Merkle, and U. P. Fringeli, "Interfacial adsorption and aggregation associated changes in secondary structure of human calcitonin monitored by ATR-FTIR spectroscopy," Biochemistry, vol. 33, no. 40, pp. 12276-12282, 1994.

[158] T. Arvinte, A. Cudd, and A. F. Drake, "The structure and mechanism of formation of human calcitonin fibrils," Journal of Biological Chemistry, vol. 268, no. 9, pp. 6415-6422, 1993.

[159] T. Arvinte and A. F. Drake, "Comparative study of human and salmon calcitonin secondary structure in solutions with low dielectric constants," Journal of Biological Chemistry, vol. 268, no. 9, pp. 6408-6414, 1993.

[160] K. Kanaori and A. Y. Nosaka, "Study of human calcitonin fibrillation by proton nuclear magnetic resonance spectroscopy," Biochemistry, vol. 34, no. 38, pp. 1213812143, 1995.

[161] Y. Liu and D. Schubert, "Cytotoxic amyloid peptides inhibit cellular 3-(4,5-dimethylthiazol-2- yl)-2,5-diphenyltetrazolium bromide (MTT) reduction by enhancing MTT formazan exocytosis," Journal of Neurochemistry, vol. 69, no. 6, pp. 2285-2293, 1997.
[162] D. L. Rymer and T. A. Good, "The role of G protein activation in the toxicity of amyloidogenic $\mathrm{A} \beta-(1-40), \mathrm{A} \beta-(25-35)$, and bovine calcitonin," Journal of Biological Chemistry, vol. 276, no. 4, pp. 2523-2530, 2001.

[163] S. S. Wang, T. A. Good, and D. L. Rymer, "The influence of phospholipid membranes on bovine calcitonin secondary structure and amyloid formation," Protein Science, vol. 14, no. 6, pp. 1419-1428, 2005.

[164] S. S. Wang, T. A. Good, and D. L. Rymer, "The influence of phospholipid membranes on bovine calcitonin peptide's secondary structure and induced neurotoxic effects," International Journal of Biochemistry and Cell Biology, vol. 37, no. 8, pp. 1656-1669, 2005.

[165] C. Avidan-Shpalter and E. Gazit, "The early stages of amyloid formation: biophysical and structural characterization of human calcitonin pre-fibrillar assemblies," Amyloid, vol. 13, no. 4, pp. 216-225, 2006.

[166] P. J. Gilchrist and J. P. Bradshaw, "Amyloid formation by salmon calcitonin," Biochimica et Biophysica Acta, vol. 1182, no. 1, pp. 111-114, 1993.

[167] M. C. Gaudiano, M. Colone, C. Bombelli, P. Chistolini, L. Valvo, and M. Diociaiuti, "Early stages of salmon calcitonin aggregation: effect induced by ageing and oxidation processes in water and in the presence of model membranes," Biochimica et Biophysica Acta, vol. 1750, no. 2, pp. 134-145, 2005.

[168] M. C. Gaudiano, M. Diociaiuti, P. Bertocchi, and L. Valvo, "Effects induced by hydroxyl radicals on salmon calcitonin: a RP-HPLC, CD and TEM study," Biochimica et Biophysica Acta, vol. 1623, no. 1, pp. 33-40, 2003.

[169] H. A. Lashuel, D. Hartley, B. M. Petre, T. Walz, and P. T. Lansbury, "Neurodegenerative disease: amyloid pores from pathogenic mutations," Nature, vol. 418, no. 6895, p. 291, 2002.

[170] F. Malchiodi-Albedi, V. Contrusciere, C. Raggi et al., "Lipid raft disruption protects mature neurons against amyloid oligomer toxicity," Biochimica et Biophysica Acta, vol. 1802, no. 4, pp. 406-415, 2010.

[171] L. Haataja, T. Gurlo, C. J. Huang, and P. C. Butler, "Islet amyloid in type 2 diabetes, and the toxic oligomer hypothesis," Endocrine Reviews, vol. 29, no. 3, pp. 303-316, 2008.

[172] M. D. Ledesma, B. Brügger, C. Bünning, F. T. Wieland, and C. G. Dotti, "Maturation of the axonal plasma membrane requires upregulation of sphingomyelin synthesis and formation of protein-lipid complexes," EMBO Journal, vol. 18, no. 7, pp. 1761-1771, 1999. 


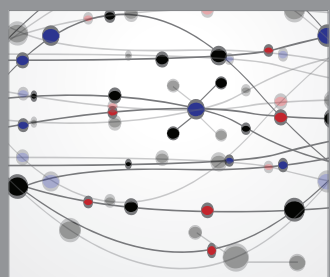

The Scientific World Journal
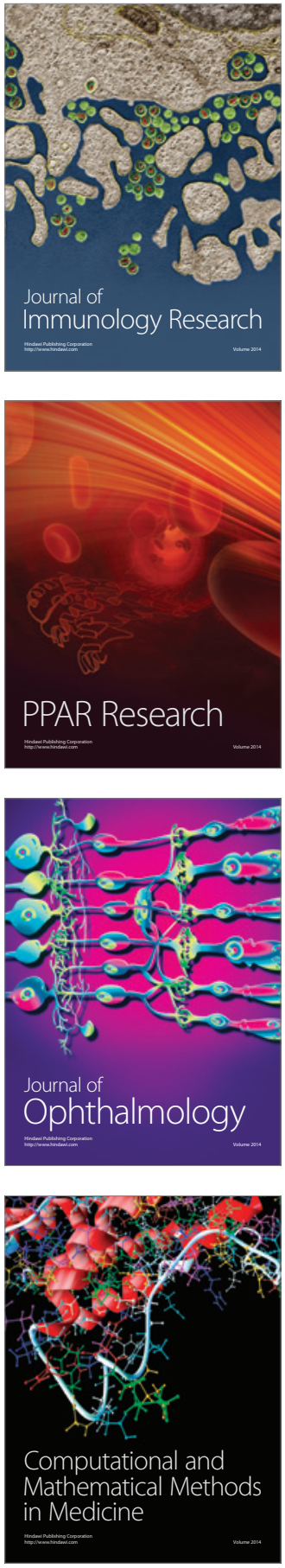

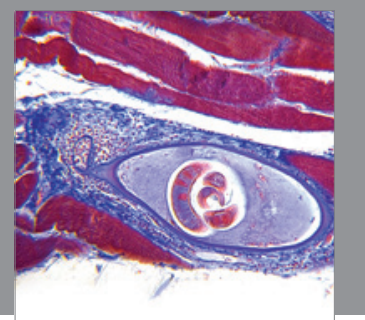

Gastroenterology

Research and Practice
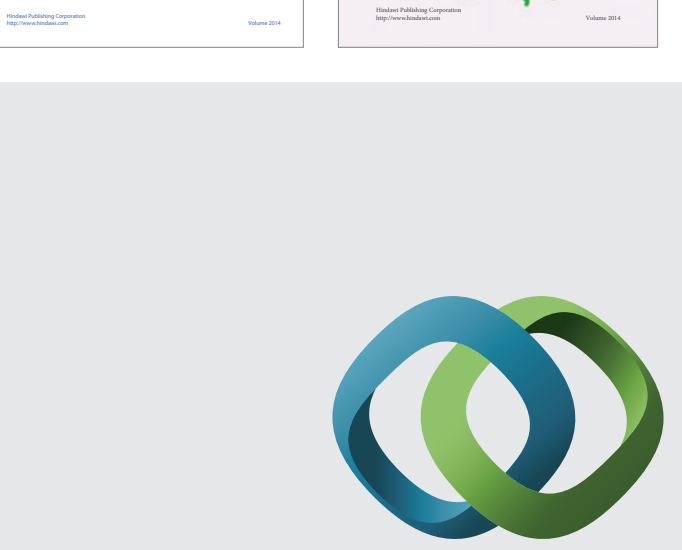

\section{Hindawi}

Submit your manuscripts at

http://www.hindawi.com
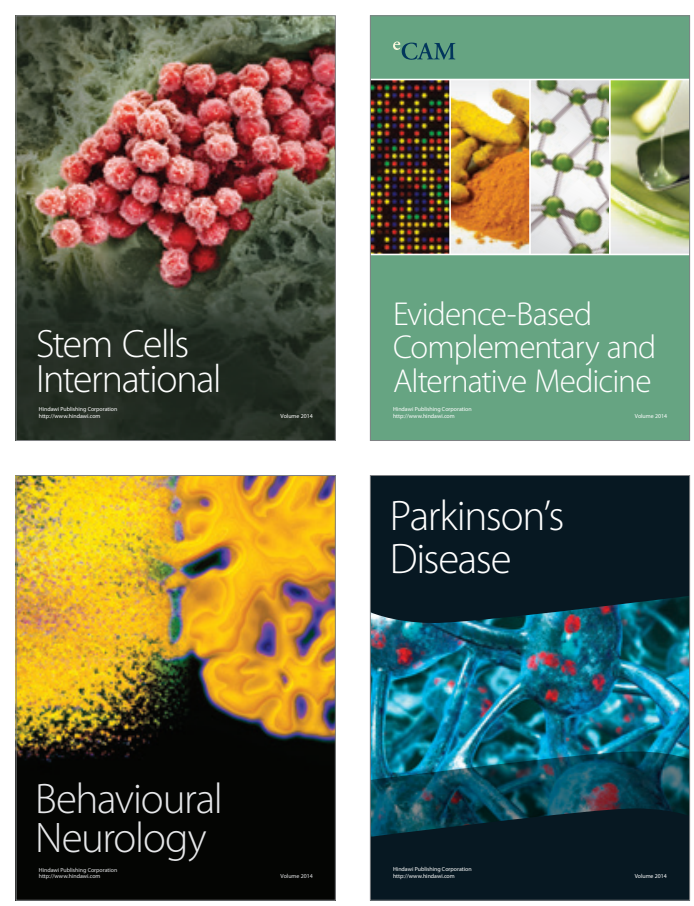

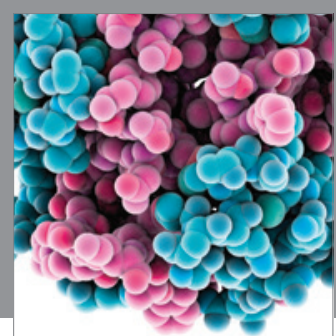

Journal of
Diabetes Research

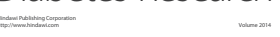

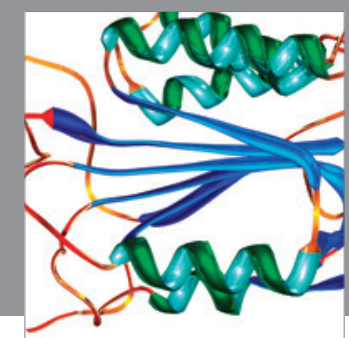

Disease Markers
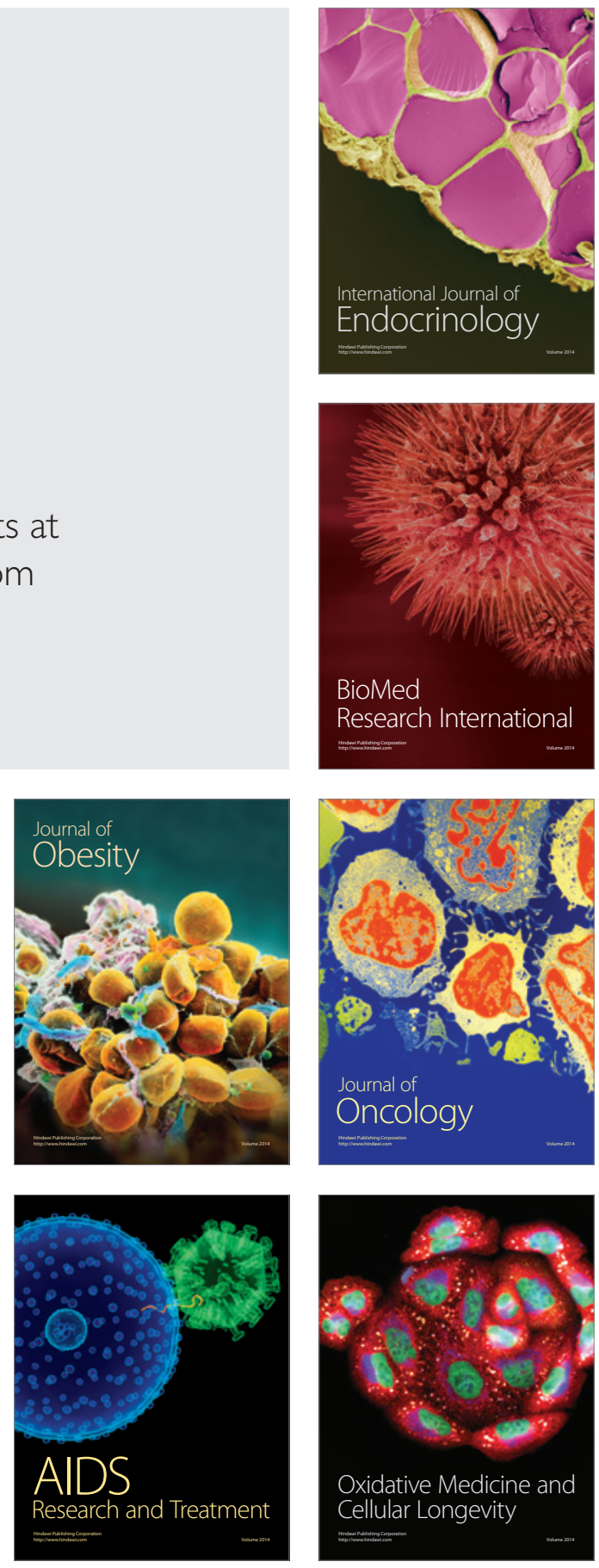